\title{
Multiphase flow modeling of asphaltene precipitation and deposition
}

\author{
Amir Tabzar ${ }^{1}$, Mohammad Fathinasab ${ }^{2,}$ Afshin Salehi $^{3}$, Babak Bahrami ${ }^{1}$, and Amir H. Mohammadi ${ }^{4, *}$ \\ ${ }^{1}$ Department of Chemical and Petroleum Engineering, Shiraz University, Shiraz, Iran \\ ${ }^{2}$ Petroleum Division, Research Institute of Petroleum Industry (RIPI), Tehran, Iran \\ ${ }^{3}$ Department of Petroleum Engineering, Petroleum University of Technology (PUT), Ahvaz, Iran \\ ${ }^{4}$ Discipline of Chemical Engineering, School of Engineering, University of KwaZulu-Natal, Howard College Campus, King George V \\ Avenue, Durban 4041, South Africa
}

Received: 10 February 2018 / Accepted: 16 July 2018

\begin{abstract}
Asphaltene precipitation in reservoirs during production and Enhanced Oil Recovery (EOR) can cause serious problems that lead to reduction of reservoir fluid production. In order to study asphaltene tendency to precipitate and change in flow rate as a function of distance from wellbore, an equation of state (Peng-Robinson) based model namely Nghiem et al.'s model has been employed in this study. The heaviest components of crude oil are separated into two parts: The first portion is considered as non-precipitating component $\left(\mathrm{C}_{31 \mathrm{~A}+}\right)$ and the second one is considered as precipitating component $\left(\mathrm{C}_{31 \mathrm{~B}+}\right)$ and the precipitated asphaltene is considered as pure solid. For determination of the acentric factor and critical properties, Lee-Kesler and Twu correlations are employed, respectively. In this study, a multiphase flow (oil, gas and asphaltene) model for an asphaltenic crude oil for which asphaltene is considered as solid particles (precipitated, flocculated and deposited particles), has been developed. Furthermore, effect of asphaltene precipitation on porosity and permeability reduction has been studied. Results of this study indicate that asphaltene tendency to precipitate increases and permeability of porous medium decreases by increasing oil flow rate in undersaturated oil reservoirs and dropping reservoir pressure under bubble point pressure. On the other hand, asphaltene tendency to precipitate decreases with pressure reduction to a level lower than bubble point pressure where asphaltene starts to dissolve back into oil phase. Moreover, it is observed that precipitation zone around the wellbore develops with time as pressure declines to bubble point pressure (production rate increases up). Also, there is an equilibrium area near wellbore region at which reservoir fluid properties such as UAOP (Upper Asphaltene Onset Pressure) and LAOP (Lower Asphaltene Onset Pressure) are constant and independent of the distance from wellbore.
\end{abstract}

\section{Nomenclature}

$B \quad$ Formation volume factor, $\mathrm{ft}^{3} / \mathrm{ft}^{3}$

D Depth, ft

E Volume fraction in bulk volume, dimensionless

$k \quad$ Permeability, $\mathrm{mD}$

LAOP Lower Asphaltene Onset Pressure

$P \quad$ Pressure, psia

$Q \quad$ Flow rate, STBD

$r \quad$ Radius

$R_{\mathrm{A}} \quad$ Dissolved asphaltene oil ratio, $\mathrm{ft}^{3} / \mathrm{ft}^{3}$

$R_{\mathrm{S}} \quad$ Solution gas-oil ratio, $\mathrm{SCF} / \mathrm{STB}$

S Saturation, fraction of void volume $t \quad$ Time, days

UAOP Upper Asphaltene Onset Pressure

$v_{\mathrm{c}} \quad$ Critical molar volume of crude component

$k_{\mathrm{ij}} \quad$ Binary interaction parameter

$v_{\text {cr,o }} \quad$ Critical interstitial oil velocity for entrainment

\section{Greek Letters}

$\alpha \quad$ Surface deposition coefficient, $1 /$ day

$\beta \quad$ Entrainment coefficient, $1 / \mathrm{ft}$

$\gamma_{i} \quad$ Pore throat plugging coefficient, $1 / \mathrm{ft}$

$\sigma \quad$ Snowball coefficient, dimensionless

$\lambda \quad$ Mobility

$\phi \quad$ Porosity, fraction of pore space

* Corresponding authors: fathinasab1369@gmail.com; amir_h_mohammadi@yahoo.com 
$\gamma \quad$ Gravity coefficient, $\mathrm{psi} / \mathrm{ft}$

$\Delta \quad$ Difference

\section{Subscripts and Superscripts}

$\begin{array}{ll}\text { A } & \text { Asphaltene } \\ \mathrm{g} & \text { Gas } \\ \mathrm{l} & \text { Phase index } \\ \mathrm{o} & \text { Oil } \\ \mathrm{w} & \text { Water }\end{array}$

\section{Introduction}

Crude oil is a blend of different hydrocarbons with various molecular weights and some heteromolecules like asphaltene which contain nitrogen, sulfur, oxygen, metal, etc. By any type of disturbance like mixing of crude oil, injection of solvent/gas during Enhanced Oil Recovery (EOR), change in reservoir fluid pressure and temperature, etc reservoir equilibrium is interrupted, and this leads to asphaltene precipitation [1-8]. However, during the life of the reservoir, temperature could be considered constant, hence change in reservoir pressure and composition could be regarded as the most important factors which affect asphaltene precipitation. The characterization of asphaltene has been investigated by some researchers. Zheng et al. [9], studied the properties of three types of asphaltene extracted from an oil sand and two vacuum residues from petroleum refining by nuclear magnetic resonance and distortion less enhancement by polarization transfer. Asphaltene structural properties for a heavy oil with $19^{\circ}$ API was investigated by Davarpanah et al. They stated that asphaltene yield achieved by normal heptane was lower compared to normal pentane with the yield ratio of $15.5 / 21.5$ [10].

Asphaltene precipitation causes formation damage which has unfavorable effects on crude oil production rate, reservoir rock permeability, porosity and wettability. Asphaltene precipitation in addition to formation plugging, can cause critical problems through wellbore and production facilities [11]. Asphaltene is defined as the heaviest fraction of crude oil that is insoluble in normal alkanes [12], yet dissolvable in aromatic solvents such as toluene and benzene [13]. Polar components with intermediate Molecular Weight (MW) called resins control asphaltene solubility and stability in crude oil. [2, 3]. Resins are known as the fraction of crude oil that is soluble in $n$-heptane but insoluble in propane. Resins have lower molecular weight compared to asphaltenes [14], however both of them are considered as polar heavy aromatics. The ratio of asphaltenes to resins for stable crude is approximately more than 1:1 while for the case of lower than this ratio, the crude oil is unstable in terms of asphaltene solubility, and asphaltene tends to precipitate.

It has been appeared through phase behavior studies that asphaltene precipitation typically begins to occur at a pressure higher than bubble point pressure which is called

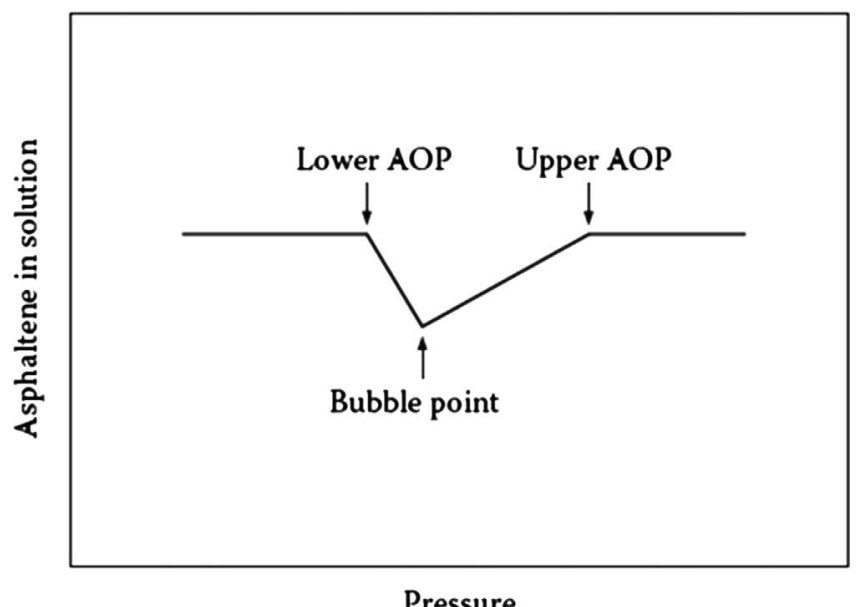

Pressure

Fig. 1. Asphaltenes solubility in crude oil versus pressure [16].

Upper Asphaltene Onset Pressure (UAOP). Then, as reservoir fluid pressure decreases, the amount of asphaltene which is precipitated increases. The maximum precipitation is occurred at the reservoir bubble pressure. Hereafter, when reservoir pressure falls below the bubble point pressure, asphaltene tends to dissolve back into the crude phase. [15]. Figure 1 shows the quantity of dissolved asphaltene in crude oil as a function of reservoir pressure [16]. As can be seen, the amount of dissolved asphaltenes in oil is constant until the pressure reaches to UAOP, after that the amount of dissolved asphaltene decreases and the precipitated asphaltene value increases. At the bubble point pressure, the dissolved asphaltene in oil reaches to its minimum value, therefore the amount of precipitated asphaltenes is in its highest value. As pressure decreases, the precipitated asphaltenes start to dissolve back into oil phase up to Lower Asphaltene Onset Pressure (LAOP) at which reaches to a constant amount.

Experimental data reported on asphaltene precipitation and dissolution at reservoir temperature and pressure is limited due to tedious and costly processes. Moreover, carrying out of field experiments for the diagnosis of this phenomenon is a challenging process. Therefore, during the design of comprehensive reservoir management strategies, both modeling and experimental measurements should be further developed. Although thermodynamic models of asphaltene precipitation can be employed for prediction of asphaltene precipitation and its value, the complexity of asphaltene causes impossibility in presentation of a fully predictive model. Therefore, experimental data should be employed for tuning the models. Recent experimental evidence has leaned toward the asphaltene precipitation reversibility [17-21].

Although some investigators have tried to model the asphaltene precipitation effects on oil reservoirs, these investigators' models accompany with some limitations $[1,7,11,15,20]$. Also, formation damage by asphaltene deposition during primary oil recovery has been studied by some researchers. Wang and Civan [22], modeled formation damage caused by asphaltene deposition. They stated 
that the heaviest formation damage for low flow rate and vertical wells can be occurred in near of wellbore. A twophase model for prediction of asphaltene and paraffin deposition was developed by Civan. Both dynamic surface and pore throat plugging were considered by Civan, but static surface was not considered [23]. Mansoori [24] studied the modeling of asphaltene and heavy organics precipitation in crude oil. He stated that asphaltene precipitation is an irreversible process among heavy organic precipitation/deposition and that is why a thermodynamic model fails in the prediction of asphaltene precipitation envelopes accurately. Asphaltene precipitation happens by changing the reservoir conditions and its properties. Gas injection into reservoir can alter the reservoir condition and fluid properties. A mass transfer model for determining partition coefficient between oil and water was proposed by Hutin et al. and also, the effect of asphaltene type on the mass transfer and Interfacial Tension (IFT) was investigated. They showed up that at interface between oil-water the behavior of crude oil can be regenerated by asphaltene [25]. Manshad et al. [26], investigated the precipitation of asphaltene during gas injection process by using of artificial neural network-particle swarm optimization algorithm. Bahrami et al. investigated the effect of various injected gases on the asphaltene phase behavior. The results of their work show that except for carbon dioxide, gas injection expands the asphaltene phase envelope. Also, $\mathrm{CO}_{2}$ could be considered as an asphaltene stabilizer agent below certain temperature [27].

Srivastava and Huang [28] investigated the asphaltene precipitation during $\mathrm{CO}_{2}$ flooding. The results of their work show that the most important factor affecting asphaltene precipitation/flocculation is the concentration of $\mathrm{CO}_{2}$ or injected gas into reservoir fluid. Wang and Civan [1] studied the decrease in productivity of horizontal and vertical wells caused by asphaltene precipitation in oil reservoirs. They stated that during the 3 years period of production, for both vertical and horizontal wells, productivity index declined more than $50 \%$. Also, they stated that asphaltene precipitation pattern in the reservoir for both of wells was different from each other. Asphaltene deposition also has been investigated in laboratory core tests. Asphaltene and paraffin were simultaneously analyzed by laboratory core tests and modeling by Wang and Civan [29]. Papadimitriou et al. [30] investigated the asphaltene precipitation mechanism during oil flow through core samples. Results of their work reveal that core permeability has a vital role in the precipitation and stability of asphaltene at which the core is more permeable, the precipitated asphaltenes are more stable. Moreover, the effects of ultrasonic wave radiation on asphaltene aggregation in toluene-pentane mixture have been investigated by Mousavi et al. [31]. They used heavy and extra heavy crude oils in their experiments and stated that the alterations occurred by this technology is more significant for heavier crude oil. Solaimany-Nazar and Zonnouri [32] investigated asphaltene precipitation through reservoir formation during primary oil recovery. The results of their modeling show that the most crucial factor in asphaltene precipitation in oil reservoirs is the crude oil production rate. Also, they stated that initial permeability of the formation has a vital role on the formation damage. Kazemzadeh et al. [33] investigated the effect of $\mathrm{Fe}_{3} \mathrm{O}_{4}$ nanoparticles on asphaltene precipitation during $\mathrm{CO}_{2}$ injection. They stated that the performance of nanoparticles in retarding asphaltene precipitation is substantially depend on the type of asphaltene in the solution. They used two different types of asphaltenes and found that asphaltene precipitation is further reduced in the heavier solution. Kashefi et al. studied the adsorption capacity of asphaltene by zeolite beta nanoparticles in order to decrease its deposition. Their results reveal that asphaltene in solution can be adsorbed by beta zeolite nanoparticles with optimum concentrations of $10 \mathrm{~g} / \mathrm{L}$ of beta zeolite nanoparticles in oil [34]. Moreover, Rezakazemi et al. used aluminum oxide nanoparticles in order to separate asphaltene from oil [35].

There are two standpoints in the case of asphaltene presence in crude oil. In the first one, the precipitated asphaltene like other crude oil components is reversible. This standpoint is useful in justification of thermodynamic models that relate asphaltene precipitation to crude composition, pressure, and temperature. In the second one, the precipitated asphaltene is not reversible due to interaction of stabilized asphaltene in reservoir fluid with resins, therefore colloid formation [15].

Although asphaltene precipitation has been studied by some researchers in the past decades [15, 24, 32], there is no comprehensive study on the asphaltene tendency to precipitate and deposit through formation in vicinity of evolved gas. Highlighting the contribution of the article, in this study the asphaltene precipitation, deposition and plugging are studied in both saturated and under-saturated reservoirs. In this study, a multiphase (oil, gas and asphaltene) flow model has been developed to investigate asphaltene precipitation, deposition and plugging in saturated and under-saturated oil reservoirs in cylindrical coordinates. Moreover, the effects of time, production rate and free gas have been investigated on asphaltene precipitation tendency, suspended asphaltene saturation and the formation porosity and permeability reduction. Also, the variation of reservoir fluid properties such as Upper Asphaltene Onset Pressure and Lower Asphaltene Onset Pressure with time and distance from wellbore has been investigated.

\section{Theory and modeling}

\subsection{Thermodynamic model}

In order to investigate the effect of asphaltene precipitation and deposition on reservoir rock and fluid properties, a compositional simulator has been employed. In this work, in order to model asphaltene precipitation the model proposed by Nghiem et al. [36] has been employed. This model assumes that the heaviest components of crude can be divided into two parts. The first portion can be considered as non-precipitating solid $\left(\mathrm{C}_{31 \mathrm{~A}+}\right)$ and the second one that is considered as precipitating component $\left(\mathrm{C}_{31 \mathrm{~B}+}\right)$. According to their proposed model, the precipitated asphaltene is 
Table 1. Asphaltene precipitation model parameters.

\begin{tabular}{lc}
\hline Parameter & Value \\
\hline$P^{*}(\mathrm{psia})$ & 5000 \\
$V_{\mathrm{S}}(\mathrm{L} / \mathrm{mol})$ & 0.8 \\
$f_{s}^{*}$ & $8.1 \times 10^{-9}$ \\
\hline
\end{tabular}

considered as pure solid in which fugacity is calculated from following equation:

$$
\ln f_{\mathrm{S}}=\ln f_{\mathrm{s}}^{*}+\frac{V_{\mathrm{S}}\left(P-P^{*}\right)}{\mathrm{RT}}
$$

where $f_{\mathrm{s}}$ and $f_{\mathrm{s}}^{*}$ denote the fugacity of precipitated solid at the pressure of $P$ and reference pressure of $P^{*}$, respectively. $V_{\mathrm{s}}$, denotes the molar volume of precipitated solid and its typical value is $0.8 \mathrm{~L} / \mathrm{mol}$. Also, $P^{*}$ typically is considered as upper asphaltene onset pressure. The model parameters are reported in Table 1.

In order to determine equilibrium composition of coexisting phases and the phases fractions, Peng-Robinson [37] equation of state has been employed. During production under reservoir temperature and pressure, number of phases which exist in each grid block is unknown at the point of the start of the analysis, so in order to determine phase numbers, the phase stability analysis has been done. The flowchart of the applied phase stability analysis is illustrated in Figure 2.

\subsubsection{Fluid characterization}

The composition of the reservoir fluid is reported in Table 2. Since through any compositional reservoir simulation, the fluid characterization has an essential role, for $\mathrm{C}_{7}{ }^{+}$splitting the gamma probability function [38] (the most widely used function) has been employed. Table 3 shows that after grouping, all the components are lumped into 16 components. In order to determine of the acentric factor and critical properties of the lumped components and the end fraction $\left(\mathrm{C}_{31+}\right)$ Lee and Kesler [39] and Twu [40] correlations have been employed, respectively, while for the rest of the crude components these properties have been obtained from literature [41]. It should be mentioned that the binary interaction coefficients employed in equation of state, for pure components have been obtained from literature [41], and for other components except the precipitating one $\left(\mathrm{C}_{31 \mathrm{~B}+}\right)$ have been calculated by the following equation [42]:

$d_{i k}=1-\left(\frac{2 v_{c i}^{\frac{1}{6}} v_{c k^{\frac{1}{6}}}}{v_{c i^{\frac{1}{3}}}+v_{c k^{\frac{1}{3}}}}\right)^{e}, \quad i=1,2, \ldots, N_{C}, \quad k=1,2, \ldots, N_{C}$

where $d_{i k}$ denotes the binary interaction coefficient between $i$ th and $k$ th components, $v_{c k}$ is the critical molar volume of $k$ th component and e is a constant which is calculated for equation of state. On the other hand, the binary interaction coefficient between the precipitating component $\left(\mathrm{C}_{31 \mathrm{~B}+}\right)$ and crude components with carbon number of six and more than that is considered zero while the binary interaction coefficient between the precipitating component $\left(\mathrm{C}_{31 \mathrm{~B}+}\right)$ and crude components with carbon number of less than six is estimated by tuning of the percent of asphaltene precipitation at different pressures and its value which is considered constant is 0.4. In this study, in order to optimize process, Pattern Search method which is one of the MATLAB's Optimization Toolboxes has been employed. In fact Pattern Search method determines the model parameters through an iterative process. The asphaltene precipitation information is reported in Table 4.

\subsection{Asphaltene deposition and plugging model}

There are three factors which contribute to asphaltene precipitation rate including deposition on the surface, deposits entrainment and plugging of the pore throat. Ali and Islam [43], Wang and Civan [1] and Almehaideb [15] employed all of these parameters in modeling of the process of asphaltene precipitation. Their equation is as follow:

$$
\frac{\delta\left(E_{\mathrm{A}}\right)}{\delta t}=\alpha C_{s f, v} \emptyset-\beta E_{\mathrm{A}}\left(v_{\mathrm{o}}-v_{\mathrm{cr}, \mathrm{o}}\right)+\gamma_{i}\left(1+\sigma E_{\mathrm{A}}\right) u_{o} C_{s f, v}
$$

where $E_{\mathrm{A}}$ denotes the precipitated asphaltene volume fraction in the bulk volume, $t$ denotes time, $\alpha$ is the rate constant of the surface precipitation, $C_{s f, v}$ is the suspended asphaltene volume ratio in the oil phase, $\emptyset$ is the porosity, $u_{\mathrm{o}}$ is Darcy velocity of oil phase, $v_{\mathrm{o}}$ is the interstitial velocity of oil phase and $v_{\text {cr,o }}$ is the critical interstitial velocity of oil phase which is needed for entrainment. The first term on the right hand side illustrates surface precipitation, the second one is related to entrainment of precipitations and the third one is due to the pore throat plugging rate. The entrainment rate constant $(\beta)$ is zero when interstitial velocity $\left(v_{\mathrm{o}}\right)$ is lower than the critical interstitial velocity of oil phase $\left(v_{\text {cr.o }}\right)$, and plugging coefficient of pore throat $\left(\gamma_{i}\right)$ is zero when the channel is un-pluggable and $\sigma$ is snowball rate constant.

To represent porosity reduction through asphaltene precipitation, plugging model was used which shows reduction of porosity as a function of amount of the fractional pore volume occupied by the precipitated asphaltene [15].

$$
\emptyset=\emptyset_{0}-E_{\mathrm{A}}
$$

where $\emptyset_{0}$ is the initial porosity. Reduction of permeability as a function of asphaltene precipitation is modeled in various ways [19, 20, 43, 44]. Civan et al. [45] modeled permeability reduction through asphaltene precipitation process as below formula which relates reduction of permeability as a function of porosity:

$$
k=k_{0}\left(\frac{\phi}{\phi_{0}}\right)^{3} .
$$

Parameters of $k$ and $k_{0}$ are the permeability and the initial permeability, respectively. 


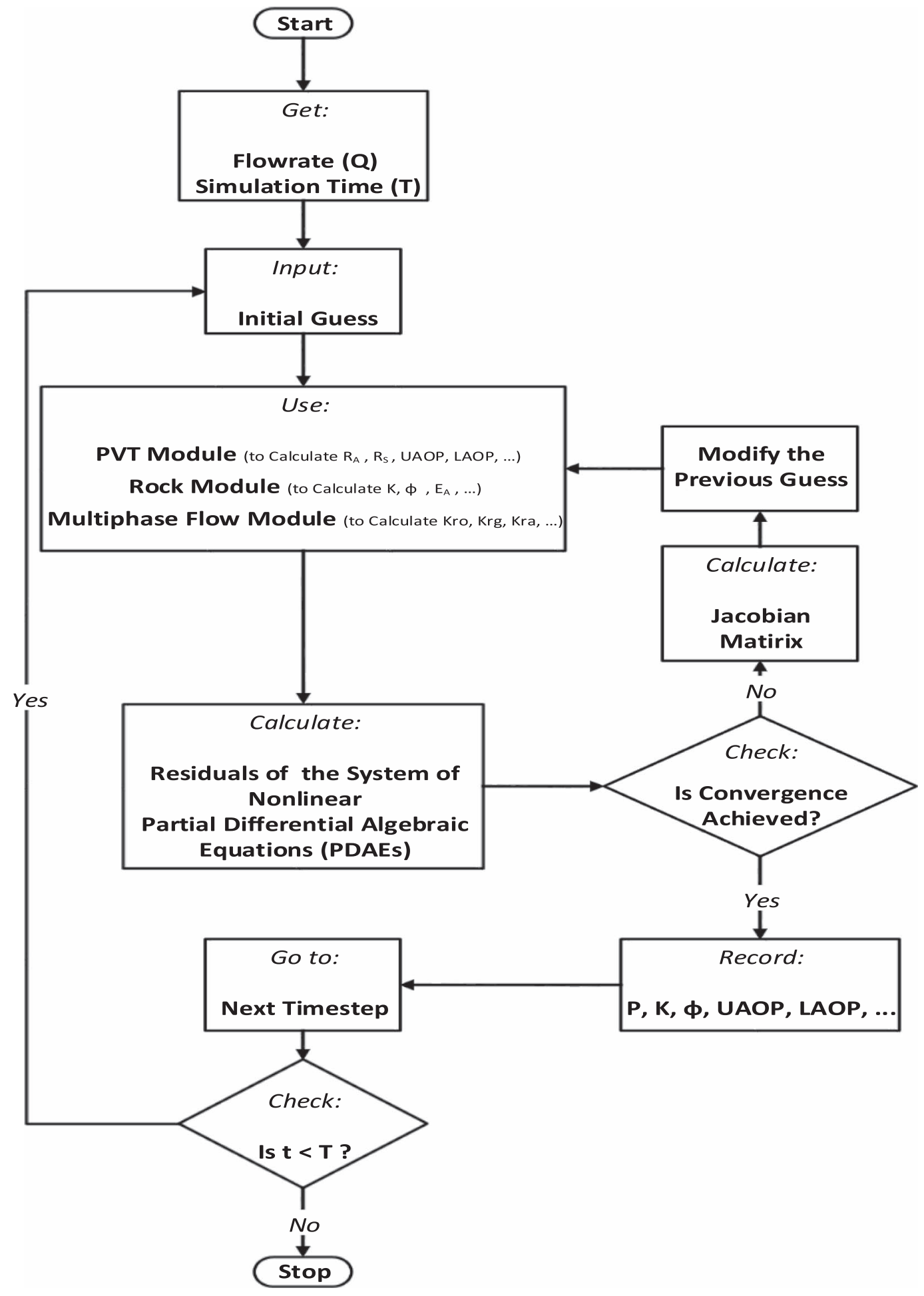

Fig. 2. Flowchart for iterative process.

\subsection{Asphaltene plugging single well model}

In order to simulate asphaltene precipitation in near wellbore region, Almehaideb [15] proposed a four phase single well model. In fact the fourth material balance equation is related to asphaltene component. The cylindrical coordinate equations of the model are as follows:
Oil phase:

$$
\begin{gathered}
\frac{1}{\mathrm{r}} \frac{\partial}{\partial \mathrm{r}}\left[r \lambda_{\mathrm{o}}\left(\frac{\partial p_{\mathrm{o}}}{\partial r}-\gamma_{\mathrm{o}} \frac{\partial D}{\partial r}\right)\right]+\frac{\partial}{\partial z}\left[\lambda_{\mathrm{o}}\left(\frac{\partial p_{\mathrm{o}}}{\partial z}-\gamma_{\mathrm{o}} \frac{\partial D}{\partial z}\right)\right] \\
=\frac{S_{\mathrm{o}}}{B_{\mathrm{o}}} \frac{\partial \emptyset}{\partial t}+\frac{\emptyset}{B_{\mathrm{o}}} \frac{\partial S_{\mathrm{o}}}{\partial t}+\emptyset S_{\mathrm{o}} \frac{\partial}{\partial t}\left(\frac{1}{B_{\mathrm{o}}}\right)+q_{\mathrm{o}}
\end{gathered}
$$


Table 2. Compositional analysis of reservoir fluid [3].

\begin{tabular}{|c|c|}
\hline Specification & Value \\
\hline $\mathrm{CO}_{2}($ mole $\%)$ & 2.46 \\
\hline $\mathrm{N}_{2}($ mole $\%)$ & 0.57 \\
\hline $\mathrm{C}_{1}($ mole $\%)$ & 36.37 \\
\hline $\mathrm{C}_{2}($ mole $\%)$ & 3.47 \\
\hline $\mathrm{C}_{3}($ mole $\%)$ & 4.05 \\
\hline$i-\mathrm{C}_{4}($ mole $\%)$ & 0.59 \\
\hline$n-\mathrm{C}_{4}($ mole $\%)$ & 1.34 \\
\hline$i-\mathrm{C}_{5}($ mole $\%)$ & 0.74 \\
\hline$n-\mathrm{C}_{5}($ mole $\%)$ & 0.83 \\
\hline $\mathrm{FC}_{6}($ mole $\%)$ & 1.62 \\
\hline $\mathrm{C}_{7}^{+}($mole $\%)$ & 47.96 \\
\hline $\mathrm{C}_{7}^{+}$molecular weight & 329 \\
\hline $\mathrm{C}_{7}^{+}$specific gravity at $212^{\circ} \mathrm{F}$ & 0.9541 \\
\hline Stock tank oil API & 19 \\
\hline Saturation pressure (psia) & 2050 \\
\hline
\end{tabular}

Water phase:

$$
\begin{gathered}
\frac{1}{r} \frac{\partial}{\partial r}\left[r \lambda_{\mathrm{w}}\left(\frac{\partial p_{\mathrm{w}}}{\partial r}-\gamma_{\mathrm{w}} \frac{\partial D}{\partial r}\right)\right]+\frac{\partial}{\partial z}\left[\lambda_{\mathrm{w}}\left(\frac{\partial p_{\mathrm{w}}}{\partial z}-\gamma_{\mathrm{w}} \frac{\partial D}{\partial z}\right)\right] \\
\quad=\frac{S_{\mathrm{w}}}{B_{\mathrm{w}}} \frac{\partial \emptyset}{\partial t}+\frac{\emptyset}{B_{\mathrm{w}}} \frac{\partial S_{\mathrm{w}}}{\partial t}+\emptyset S_{\mathrm{w}} \frac{\partial}{\partial t}\left(\frac{1}{B_{\mathrm{w}}}\right)+q_{\mathrm{w}}
\end{gathered}
$$

Gas phase:

$$
\begin{aligned}
& \frac{1}{r} \frac{\partial}{\partial r}\left[r \lambda_{\mathrm{g}}\left(\frac{\partial p_{\mathrm{g}}}{\partial r}-\gamma_{\mathrm{g}} \frac{\partial D}{\partial r}\right)+r R_{\mathrm{S}} \lambda_{\mathrm{o}}\left(\frac{\partial p_{\mathrm{o}}}{\partial r}-\gamma_{\mathrm{o}} \frac{\partial D}{\partial r}\right)\right] \\
& +\frac{\partial}{\partial z}\left[\lambda_{\mathrm{g}}\left(\frac{\partial p_{\mathrm{g}}}{\partial z}-\gamma_{\mathrm{g}} \frac{\partial D}{\partial z}\right)+R_{\mathrm{S}} \lambda_{\mathrm{o}}\left(\frac{\partial p_{\mathrm{o}}}{\partial z}-\gamma_{\mathrm{o}} \frac{\partial D}{\partial z}\right)\right] \\
& =\frac{\partial}{\partial t}\left(\frac{R_{\mathrm{S}} S_{\mathrm{o}} \phi}{B_{\mathrm{o}}}+\frac{S_{\mathrm{g}} \phi}{B_{\mathrm{g}}}\right)+q_{\mathrm{g}}+R
\end{aligned}
$$

Asphaltene phase:

$$
\begin{aligned}
\frac{1}{r} & \frac{\partial}{\partial r}\left[r\left(\lambda_{\mathrm{A}}+R_{\mathrm{A}} \lambda_{\mathrm{o}}\right)\left(\frac{\partial p_{\mathrm{o}}}{\partial r}-\gamma_{\mathrm{o}} \frac{\partial D}{\partial r}\right)\right] \\
& +\frac{\partial}{\partial z}\left[\left(\lambda_{\mathrm{A}}+R_{\mathrm{A}} \lambda_{\mathrm{o}}\right)\left(\frac{\partial p_{\mathrm{o}}}{\partial z}-\gamma_{\mathrm{o}} \frac{\partial D}{\partial z}\right)\right] \\
& =\frac{\partial}{\partial t}\left(\frac{R_{\mathrm{A}} S_{\mathrm{o}} \phi}{B_{\mathrm{o}}}+\frac{S_{\mathrm{A}} \phi}{B_{\mathrm{A}}}+\frac{E_{\mathrm{A}}}{B_{\mathrm{A}}}\right)+q_{\mathrm{o}}\left(\frac{S_{\mathrm{A}}}{S_{\mathrm{o}}}+R_{\mathrm{A}}\right)
\end{aligned}
$$

where $p$ is the phase pressure (gas (g), oil (o), water (w) and asphaltene (A)) and $S$ is the saturation of these phases. $B$ and $q$ are the formation volume factor and the production rate, respectively. $D$ is the depth, and $r$ and $z$ are the dimensions in radial and vertical directions respectively. $R_{\mathrm{A}}$ and $S_{\mathrm{A}}$ are the dissolved asphaltene volume ratio and the suspended asphaltene saturation in oil phase, respectively. Also, $\gamma$ and $\lambda$ are the phase mobility and the gravity, respectively.
The saturation of these phases are connected to each other through:

$$
S_{\mathrm{o}}+S_{\mathrm{w}}+S_{\mathrm{g}}+S_{\mathrm{A}}=1 .
$$

The following equation can be employed in phase mobility calculations:

$$
\lambda_{l}=\frac{k \times k_{r l}}{\mu_{l}},
$$

where $l$ is phase (oil, water and gas) index, $k_{r l}$ and $\mu_{l}$ are the relative permeability and the viscosity, respectively. Due to suspension of precipitated asphaltene through oil phase, same velocity for both oil and asphaltene phases can be assumed, so the mobility of these phases is represented by following equations:

$$
\lambda_{\mathrm{o}}=\frac{k \times k_{\mathrm{ro}}}{\mu_{\mathrm{o}}}\left(\frac{S_{\mathrm{o}}}{S_{\mathrm{o}}+S_{\mathrm{A}}}\right)
$$

$$
\lambda_{\mathrm{A}}=\frac{k \times k_{\mathrm{ro}}}{\mu_{\mathrm{o}}}\left(\frac{S_{\mathrm{A}}}{S_{\mathrm{o}}+S_{\mathrm{A}}}\right) .
$$

In addition, the gravitational coefficient, $\gamma_{l}$, is determined by the following equation:

$$
\gamma_{l}=\rho_{l, \mathrm{std}} \times \frac{g}{g_{\mathrm{c}}} \times \sin (\theta)
$$

where $\rho_{1, \text { std }}$ is the density of $l$ (oil, water and gas) phase under standard conditions and $\theta$ is the deviation angle. Also, $g$ and $g_{\mathrm{c}}$ are gravity acceleration. The pressure phases are connected by the capillary pressure concept $\left(P_{\mathrm{c}}\right)$ as follow:

$$
P_{\text {cow }}=P_{\mathrm{o}}-P_{\mathrm{w}} \text { and } P_{\text {cgo }}=P_{\mathrm{g}}-P_{\mathrm{o}} .
$$

In order to calculate the precipitated asphaltene values through the formation (in the Eq. (7)), the following equation [15] is employed:

$$
E_{\mathrm{A}}=E_{\mathrm{A}}+\left(\frac{\partial E_{\mathrm{A}}}{\partial t}\right) \Delta t
$$

$\frac{\partial E_{\mathrm{A}}}{\partial t}$, precipitation rate is calculated using equation (1) and $\Delta t$ is time step.

\subsection{Solution method}

Simultaneous Solution method has been employed to simulate three phase flow (oil, gas and asphaltene) in porous media. All of the equations are solved numerically by coding in Matlab software and ready-made simulator has not been used. Oil phase pressure, weight percent of asphaltene and gas phase have been considered as variables. Distinguished empirical relations - Standing and Glasu - are used to determine physical properties of oil and gas phases. In order to solve the non-linear systems of equations, the Newton and Jacobian matrix as a method to solve non-linear sets of equations has been employed. In fact, these systems deal 
Table 3. Compositional analysis of modeled fluid.

\begin{tabular}{lcccccc}
\hline Component & Mol\% & $\mathrm{MW}$ & $T_{\mathrm{c}}(\mathrm{K})$ & $P_{\mathrm{c}}(\mathrm{atm})$ & $V_{\mathrm{c}}(\mathrm{lit} / \mathrm{mol})$ & Acentric factor \\
\hline $\mathrm{CO}_{2}$ & 2.46 & 44.01 & 304.19 & 75.275 & 0.094 & 0.2276 \\
$\mathrm{~N}_{2}$ & 0.57 & 28.014 & 126.1 & 34.609 & 0.901 & 0.0403 \\
$\mathrm{C}_{1}$ & 36.37 & 16.043 & 190.56 & 46.897 & 0.0986 & 0.0115 \\
$\mathrm{C}_{2}$ & 3.47 & 30.07 & 305.32 & 49.681 & 0.1455 & 0.0995 \\
$\mathrm{C}_{3}$ & 4.05 & 44.096 & 369.83 & 43.3175 & 0.2 & 0.1523 \\
$i-\mathrm{C}_{4}$ & 0.59 & 58.123 & 408.14 & 37.199 & 0.2627 & 0.177 \\
$n-\mathrm{C}_{4}$ & 1.34 & 58.123 & 425.12 & 38.708 & 0.255 & 0.2002 \\
$i-\mathrm{C}_{5}$ & 0.74 & 72.15 & 460.43 & 34.477 & 0.3058 & 0.2275 \\
$n-\mathrm{C}_{5}$ & 0.83 & 72.15 & 469.7 & 34.364 & 0.313 & 0.2515 \\
$\mathrm{FC}_{6}$ & 1.62 & 84 & 510 & 33.355 & 0.348 & 0.251 \\
$\mathrm{C}_{7-12}$ & 13.57 & 125.44 & 602.85 & 26.46 & 0.4906 & 0.4084 \\
$\mathrm{C}_{13-18}$ & 9.27 & 210.46 & 721.18 & 18.053 & 0.7935 & 0.6563 \\
$\mathrm{C}_{19-24}$ & 6.46 & 292.24 & 796.48 & 13.704 & 1.0804 & 0.8616 \\
$\mathrm{C}_{25-30}$ & 4.69 & 364.04 & 851.87 & 11.019 & 1.2948 & 1.0237 \\
$\mathrm{C}_{31 \mathrm{~A}+}$ & 9.4491 & 610.2 & 1117.3 & 11.22 & 1.5461 & 1.1961 \\
$\mathrm{C}_{31 \mathrm{~B}+}$ & 4.5169 & 610.2 & 1117.3 & 11.22 & 1.5461 & 1.1961 \\
\hline
\end{tabular}

Table 4. The amount of precipitated asphaltene as a function of pressure at $212^{\circ} \mathrm{F}$ [3].

\begin{tabular}{lccc}
\hline $\begin{array}{l}\text { Pressure } \\
(\mathrm{psig})\end{array}$ & $\begin{array}{c}\text { Precipitates from live oil } \\
(\mathrm{wt} \%)\end{array}$ & $\begin{array}{c}\text { Precipitates remaining in residual stock-tank oil } \\
(\text { wt\%) }\end{array}$ & $\begin{array}{c}\text { Total precipitates } \\
(\text { wt\%) }\end{array}$ \\
\hline 1000 & 0.403 & 15.73 & 16.133 \\
2000 & 1.037 & 14.98 & 16.107 \\
3020 & 0.742 & 15.06 & 15.802 \\
4000 & 0.402 & 14.86 & 15.262 \\
\hline
\end{tabular}

with non-linear equations, so in order to linearize equations, Newton method and Jacobian matrix have been employed. Considering the employed solving method is an implicit one, this method is always stable theoretically. The flowchart of this process is shown in Figure 3.

By using proper initial guess and trial and error, Newton method is employed to achieve most accurate solution. When the difference between variables in subsequent time is smaller than convergence criteria, the answer is selected as the final answer. The convergence criteria are as follows:

$$
\Delta p_{\mathrm{o}}<1 \mathrm{psi}, \Delta S_{\mathrm{A}}<0.1 \% \text { wt and } \Delta S_{\mathrm{g}}<1 \% \text { wt. }
$$

Proper initial and boundary conditions are necessary in calculation of the sets of equations (3)-(16). In this study, the initial pressure of the reservoir is above the onset pressure of asphaltene precipitation. Therefore at $t=0$, the amount of the suspended asphaltene through formation is zero. Also, at zero time the reservoir is considered as an under saturated one therefore its pressure is above the bubble point pressure and there is no free gas. In other words, the followings are considered as initial and boundary conditions:

$$
\begin{gathered}
\text { At } t=0: E_{\mathrm{A}}=0, \quad k=k_{i} \text { and } \emptyset=\emptyset_{i} \\
P_{i}(\mathrm{psia})=5260 \text { and Initial UAOP }(\mathrm{psia})=5000 \\
\begin{aligned}
S_{\mathrm{wi}}(\%) & =20, S_{\mathrm{gi}}(\%)=0, S_{\mathrm{ai}}(\%)=0 \text { and } S_{\mathrm{oi}}(\%) \\
& =80 .
\end{aligned}
\end{gathered}
$$

The constant oil flow rate and infinite acting reservoir are considered as inner and outer boundary conditions, respectively. Its equation is as follow:

$$
Q_{t}\left(r_{\mathrm{e}}\right)=Q_{t}\left(r_{\mathrm{w}}\right) \times \exp \left(-\frac{r_{\mathrm{e}}^{2}}{4 \times \eta \times t}\right)
$$

$Q$ is the oil flow rate and $r_{\mathrm{e}}$ and $r_{\mathrm{w}}$ are the external and wellbore radiuses, respectively. The parameters of $\eta$ in equation (21) are defined as follows:

$$
\begin{gathered}
\eta=\frac{k \times M}{\emptyset \times C_{t}}, \\
M=M_{\mathrm{o}}+M_{\mathrm{g}}+M_{\mathrm{A}},
\end{gathered}
$$




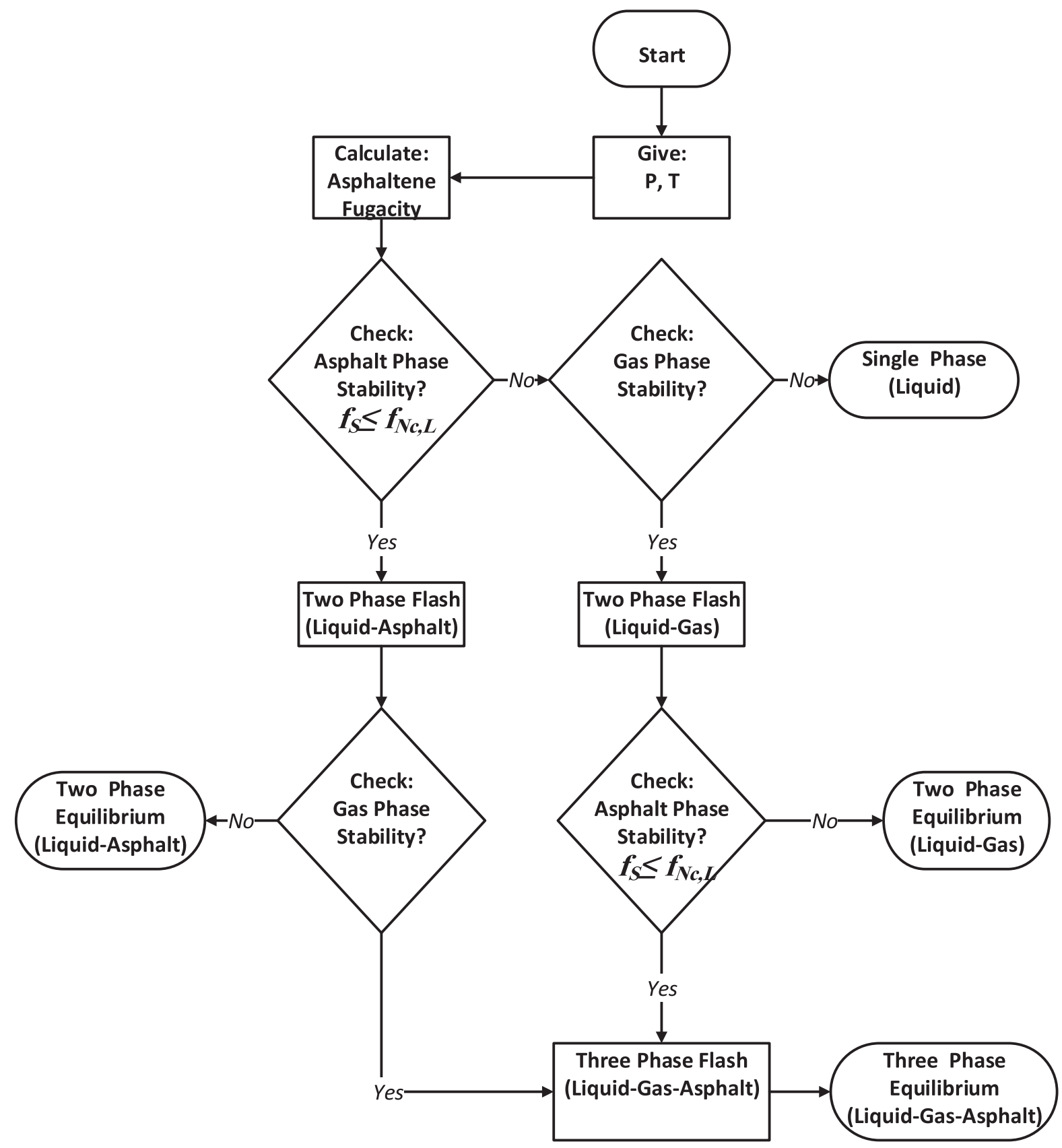

Fig. 3. Stability test flowchart for determination of the number and type of stable phases in equilibrium.

$$
\begin{gathered}
M_{\mathrm{o}}=M_{\mathrm{A}}=\frac{k_{\mathrm{ro}}}{\mu_{\mathrm{o}}}, \\
M_{\mathrm{g}}=\frac{k_{\mathrm{rg}}}{\mu_{\mathrm{g}}}, \\
C_{t}=S_{\mathrm{o}} \times C_{o}+S_{\mathrm{g}} \times C_{\mathrm{g}}+C_{r}
\end{gathered}
$$

where $\eta$ is the diffusivity constant, $M$ is the mobility, $C$ is the compressibility and $\mu$ is the viscosity.
The asphaltene precipitation, deposition and plugging model input data are from asphaltene solubility test which are reported in Table 5. The model was run for three different oil flow rates, and each one was considered in two different scenarios. The first scenario considers the precipitation of asphaltene in the pores, and the second one ignores the precipitation of asphaltene.

A crude sample with stock tank API of 19 and asphaltene content of $16.08 \%$ is considered as reservoir fluid. The LAOP, BBP and UAOP of crude sample at the temperature of $212^{\circ} \mathrm{F}$ are 387, 2009 and 5250, respectively. Basic reservoir data are reported in Tables 6 and 7 showing 
Table 5. Summary of asphaltene solubility test at $212{ }^{\circ} \mathrm{F}$ [32].

\begin{tabular}{lccc}
\hline Pressure (psia) & Precipitated asphaltene (\% of oil) & Asphaltene content (\% of oil) & $R_{\mathrm{A}}(\mathrm{STB} / \mathrm{STB})$ \\
\hline$\sim 387$ (LAOP) & 0.000 & 16.080 & 0.18736 \\
1019 & 0.403 & 15.677 & 0.18179 \\
$\sim 2009$ (BBP) & 1.034 & 15.046 & 0.17318 \\
3014 & 0.744 & 15.336 & 0.17712 \\
4005 & 0.403 & 15.677 & 0.18179 \\
$\sim 5250(\mathrm{UAOP})$ & 0.000 & 16.080 & 0.18736 \\
\hline
\end{tabular}

Table 6. Reservoir data in all runs.

\begin{tabular}{lc}
\hline \multicolumn{2}{c}{ Reservoir characteristic } \\
\hline$r_{\mathrm{e}}(\mathrm{ft})$. & Infinite \\
$r_{\mathrm{w}}(\mathrm{ft})$. & 0.5 \\
$H$ (ft.) & 50 \\
Initial porosity $(\%)$ & 25 \\
Initial permeability (md) & 100 \\
$r_{\mathrm{e}}$ (Simulation) (ft.) & 300 \\
Reservoir temperature $\left({ }^{\circ} \mathrm{F}\right)$ & 212 \\
\hline
\end{tabular}

the precipitation model constants. The overall characterization of crude oil used in this study is reported in Table 8.

\section{Results and discussion}

In order to model the asphaltene precipitation, the system was modeled in two cases of depositional and nondepositional. In depositional case, asphaltene precipitates first, then it deposits near wellbore, while in non-depositional case, asphaltene precipitates but there is no asphaltene deposition. In fact, in the non-depositional case, oil and precipitated asphaltene are in equilibrium that means oil phase is saturated with precipitated asphaltene.

In order to compare experimental and simulated values of weight percent of precipitated asphaltene, the pressure effect on the precipitated asphaltene value at $212^{\circ} \mathrm{F}$ is shown in Figure 4. As indicated in this figure, a perfect consistency between the experimental data and predicted values by the model is observed.

\subsection{Upper and lower AOP}

Figures 5A and 5B show the Reservoir Pressure (RP) through formation, Bubble Point Pressure (BPP), Upper and Lower Asphaltene Onset Pressures (UAOP and LAOP) at oil flow rates of 1000 STBD for depositional and nondepositional cases, respectively. By comparing these figures, it can be found that although in depositional case asphaltene deposition causes a decrease in permeability, hence increase in necessary pressure drop for production, since the production flow rate is not high enough, the necessary pressure drop for production and consequently the amount
Table 7. Deposition model constants [13, 27].

\begin{tabular}{lc}
\hline Parameter & Value \\
\hline$\alpha(1 /$ day $)$ & 0 and 0.01 \\
$\beta(1 / \mathrm{ft})$ & 0 \\
$\gamma_{\mathrm{i}}(1 / \mathrm{ft})$ & 0 \\
$\sigma($ constant $)$ & 0 \\
Temperature $\left({ }^{\circ} \mathrm{F}\right)$ & 212 \\
\hline
\end{tabular}

of asphaltene deposition is low. Therefore, there is no substantial change in pressure drop through reservoir in depositional and non-depositional cases. Also, since the asphaltene deposition even in a little amount causes change in reservoir fluid composition, hence change in reservoir fluid properties such as LAOP and UAOP, it is shown that LAOP and UAOP are more impressed in depositional case compared to non-depositional one. As can be seen at the 1000th days of production by the rate of 1000 STBD, the near wellbore pressure is greater than the bubble point pressure, and there is no free gas.

It should be mentioned that in non-depositional case (Fig. 5B), in low flow rates, the fluid properties such UAOP and LAOP are constant at the radiuses farther than $40 \mathrm{ft}$, while in the depositional case (Fig. 5A), the fluid properties are more impressed at the same radiuses. In both depositional and non-depositional cases, the difference between reservoir fluid pressure and UAOP at any specific distance from wellbore is the driving force for asphaltene precipitation from reservoir fluid in that point. Since in the depositional case, the further distance from wellbore means the lower driving force for asphaltene precipitation, therefore, there are lower amount of asphaltene precipitation and deposition.

Figures $6 \mathrm{~A}$ and $6 \mathrm{~B}$ show the RP, BPP, UAOP and LAOP at oil flow rates of 3000 STBD for depositional and non-depositional cases, respectively. It can be found from these figures that by increasing oil flow rates from 1000 to 3000 STBD, the pressure drop, and consequently asphaltene precipitation are more increased. Also, the reservoir pressure in all radiuses after 1000 days of production is greater than bubble point pressure, so there is no free gas in the reservoir. As can be seen in Figures 5 and 6, the fluid properties in the first $4 \mathrm{ft}$ of reservoir from wellbore are constant. Fluid velocity at the near wellbore areas is very high, therefore fluid is highly agitated. The turbulency 
Table 8. Overall crude oil characteristics.

\begin{tabular}{lc}
\hline Crude characteristics & Burke et al. $[3]$ \\
\hline Dead oil API & 19 \\
Gas specific gravity & 0.63 \\
Asphaltene density (lbm/cuft) & 60 \\
\% Asphaltene content (stock tank condition) & 16.08 \\
Temperature $\left({ }^{\circ} \mathrm{F}\right)$ & 212 \\
Live oil viscosity $(\mathrm{cp})$ (reservoir condition) & 3 \\
Dead oil viscosity $(\mathrm{cp})$ (stock tank condition) & 14 \\
UAOP (psia) & 5000 (a value that is sufficiently Lower than Pi) \\
BBP (psia) & 5050 (Reported by Solaimany-Nazar and Zonnouri [32] for this Crude) \\
LAOP (psia) & 593 (Corresponding value of UAOP and BPP) \\
\hline
\end{tabular}

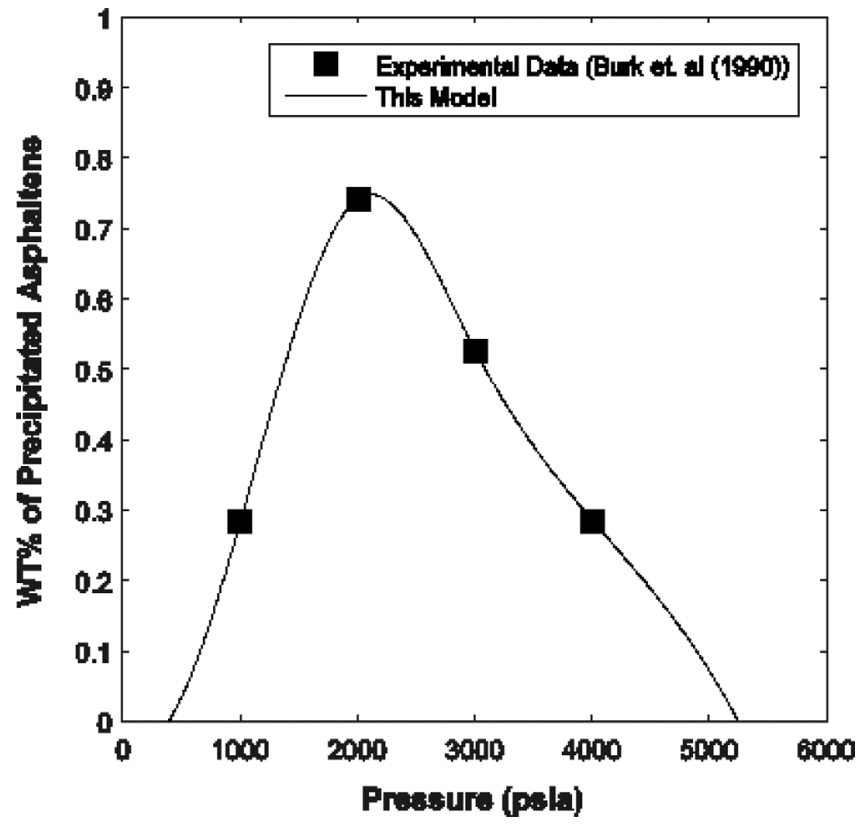

Fig. 4. Pressure effect on the amount of asphaltene precipitation in crude oil at $212^{\circ} \mathrm{F}$.

which was created by high reservoir fluid velocity near wellbore keeps the reservoir fluid properties constant at this small area. This small area is near wellbore and its radiuses are known as dynamic equilibrium area and equilibrium radius, respectively.

Figures $7 \mathrm{~A}$ and $7 \mathrm{~B}$ show the RP, BPP, UAOP and LAOP at oil flow rates of 5000 STBD and 1000 days of production for depositional and non-depositional cases, respectively. By increasing oil flow rate from 3000 to 5000 STBD, the reservoir pressure at some radiuses is dropped under bubble point pressure and gas releases from liquid phase so there is free gas in the near wellbore formation consequently. As can be seen in Figure 7A, the reservoir pressure drops under the bubble point pressure at the radius of $10 \mathrm{ft}$. Asphaltenes do precipitate in domain of below bubble pressure and down to the LAOP and the region above bubble pressure and up to the UAOP is reached. In an

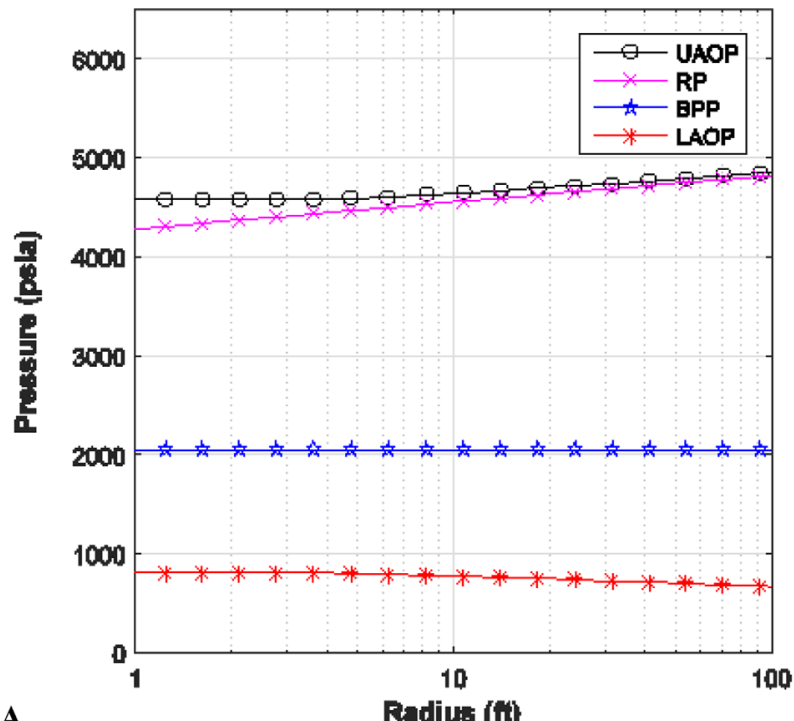

A

Radius (fi)

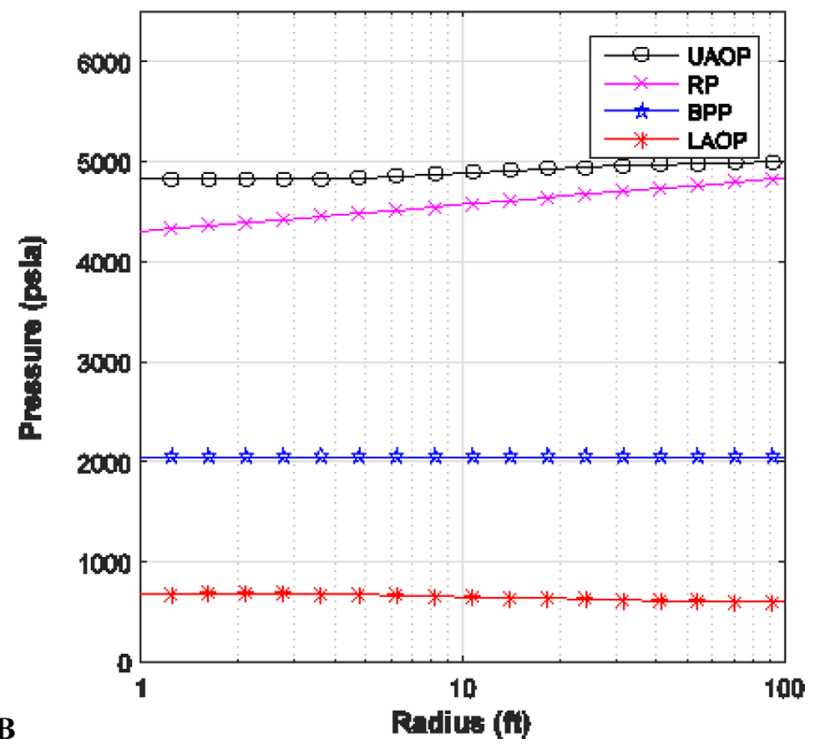

Fig. 5. Pressure behavior of an asphaltenic oil through formation at 1000 STBD for (A) depositional case, (B) nondepositional case. 

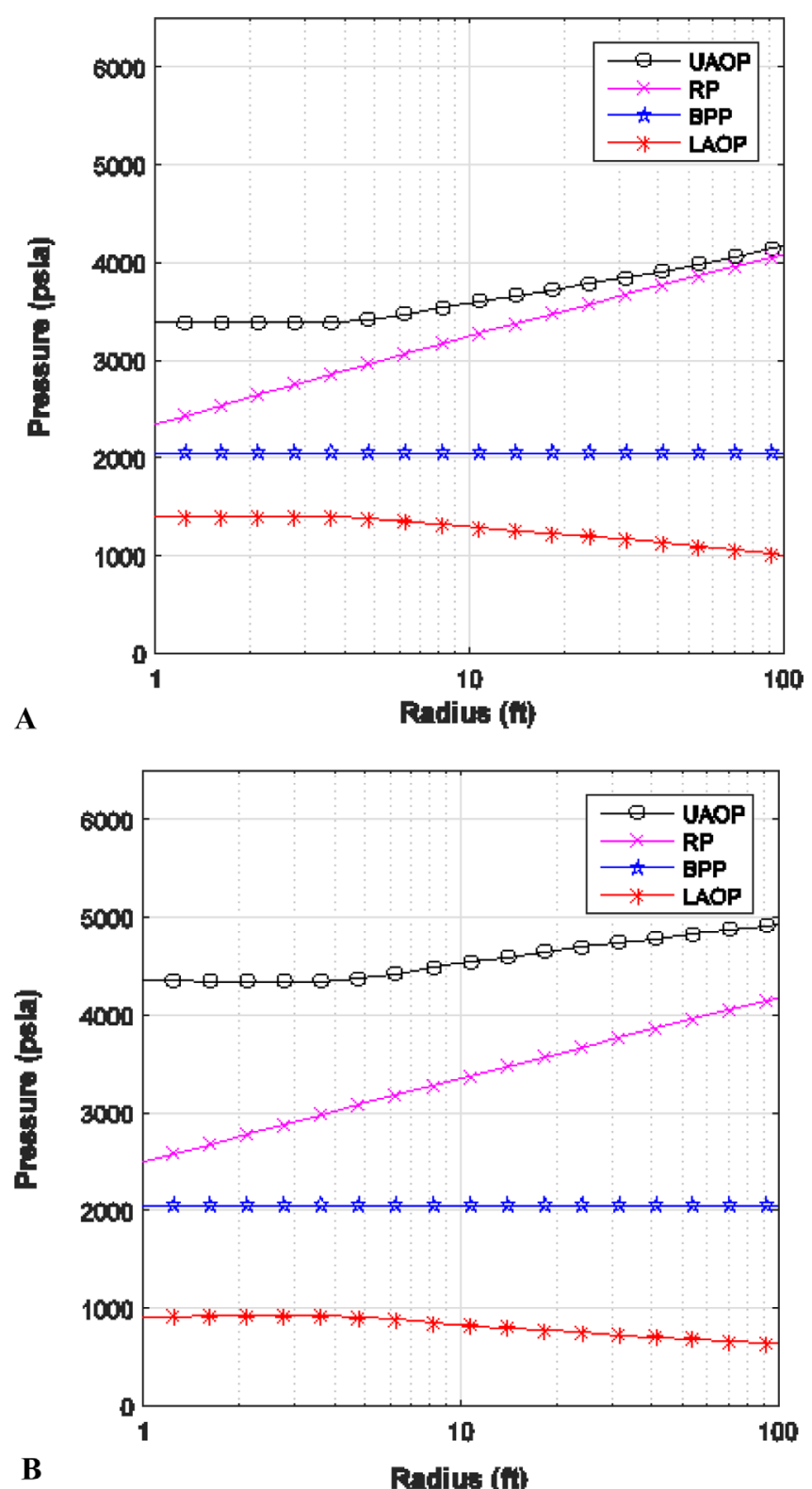

Fig. 6. Pressure behavior of an asphaltenic oil through formation at 3000 STBD for (A) depositional case, (B) nondepositional case.

asphaltenic crude oil, asphaltene precipitates as long as it is located within the unstable region (asphaltene phase envelope). At bubble pressure, the asphaltene precipitation driving force (the difference between reservoir fluid pressure and UAOP) is in its highest value. Hence, most amount of asphaltene is precipitated at the bubble pressure. With further depletion of pressure below bubble point pressure, the emission of the light components (which are known as asphaltene precipitants) from the oil will occurs. The more light components release from oil phase the more oil solubility parameter (better asphaltene solvent). This fact results to increase in asphaltene stability in crude oil when reservoir pressure decreases below bubble point pressure.
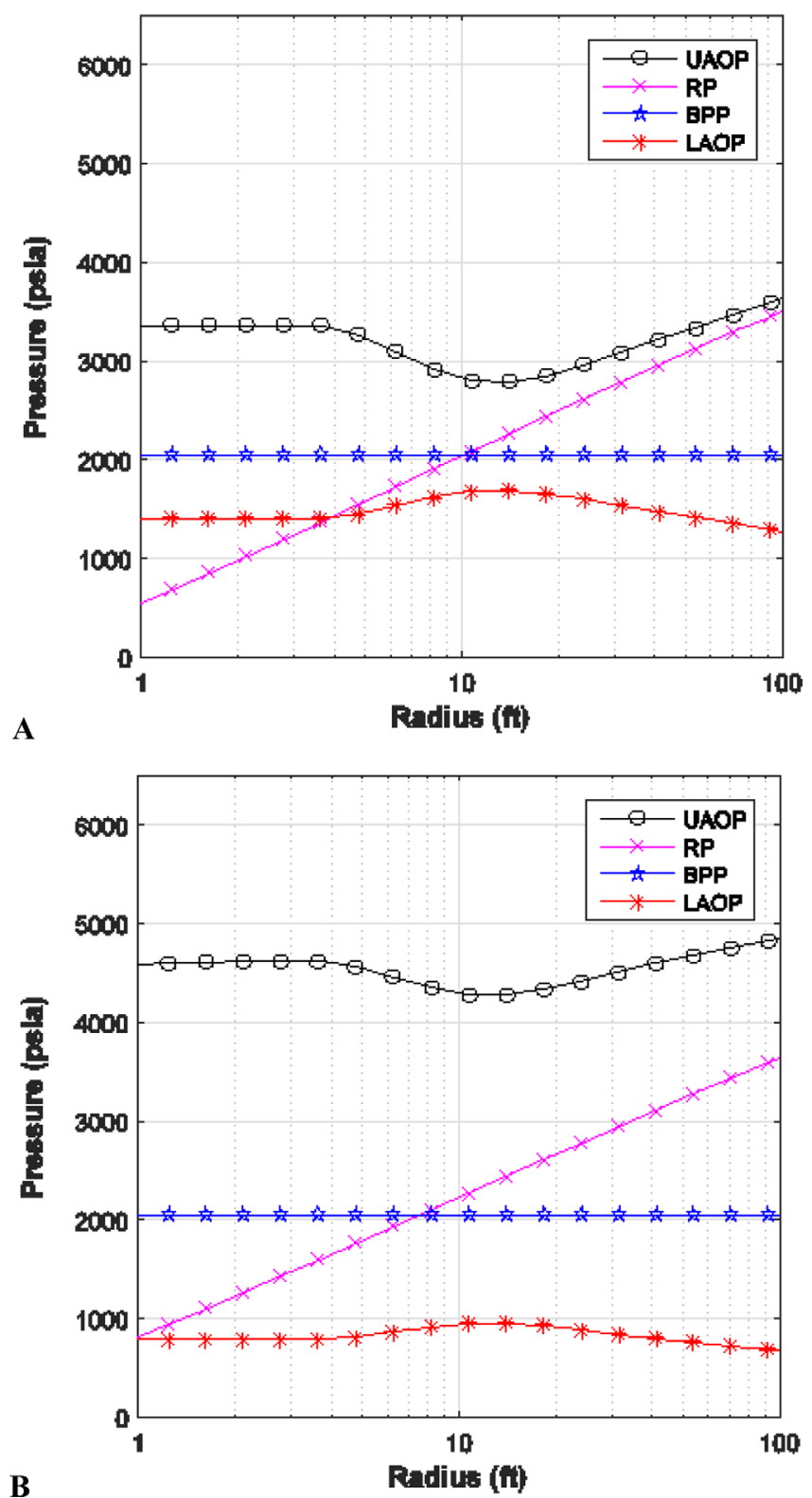

Fig. 7. Pressure behavior of an asphaltenic oil through formation at 5000 STBD for (A) depositional case, (B) nondepositional case.

\subsection{Suspended asphaltene saturation}

Figures $8 \mathrm{~A}$ and $8 \mathrm{~B}$ show the suspended asphaltene saturation at 1000 STBD near the wellbore region for depositional and non-depositional cases, respectively. As can be seen, at non-depositional case, the amount of suspended asphaltene saturation is higher compared to depositional case. It is due to the fact that in non-depositional case, all of the precipitated asphaltenes are suspended in the crude oil, and there is no deposited asphaltene. However, in depositional case some fraction of precipitated asphaltene deposits on the rock surface. Since reservoir fluid pressure through formation is higher than bubble point pressure, there is much more asphaltene precipitation driving force near wellbore 

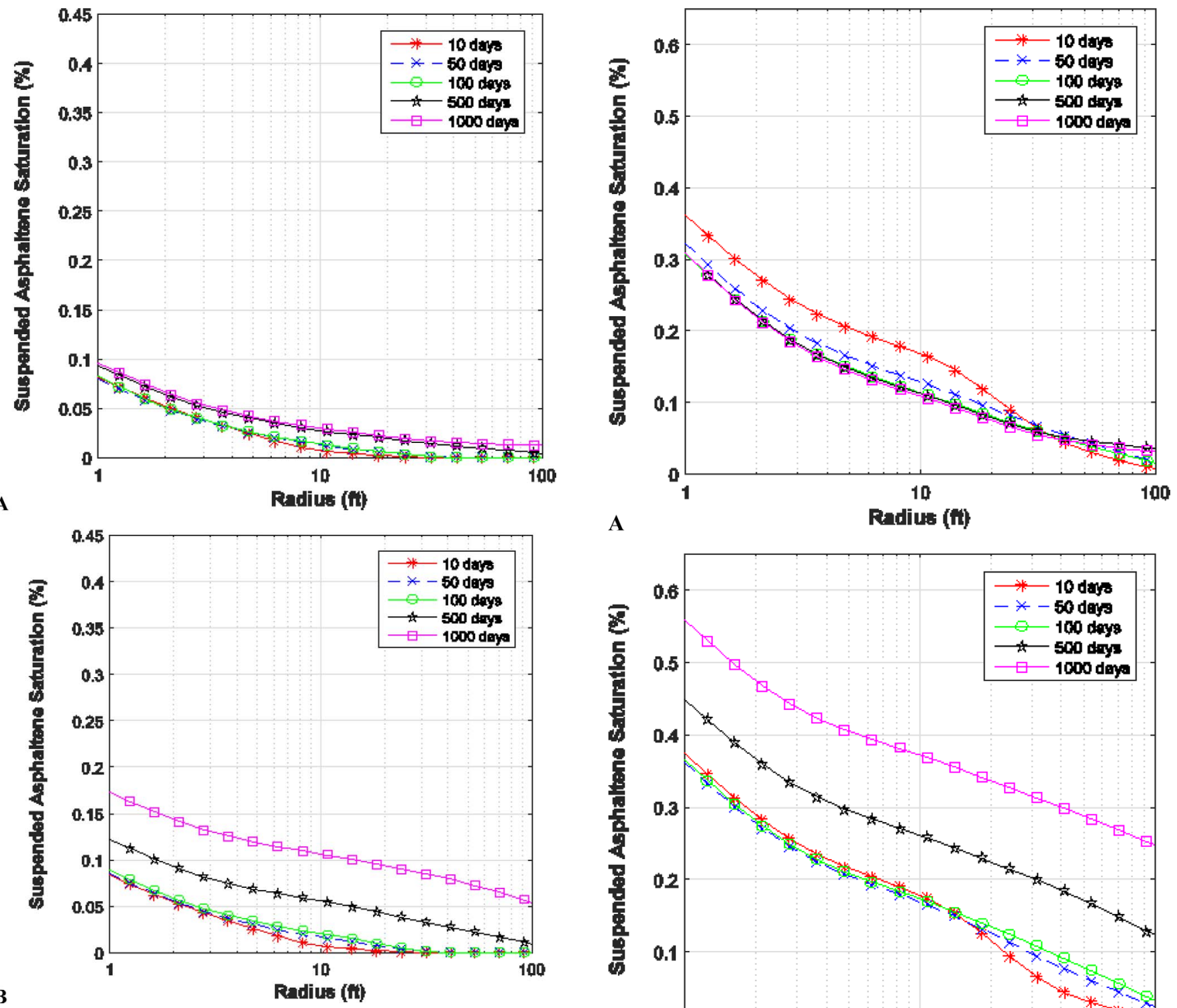

Fig. 8. Saturation of suspended asphaltene at 1000 STBD for (A) depositional case, (B) non-depositional case.

region compared to further distances. Therefore, the amount of suspended asphaltene near wellbore is higher and during time this amount is increased in the all radiuses.

Figures $9 \mathrm{~A}$ and $9 \mathrm{~B}$ show the suspended asphaltene saturation at 3000 STBD through formation for depositional and non-depositional cases, respectively. These figures show that an increase in oil flow rate to 3000 STBD causes an increase in the amount of precipitated asphaltene for both depositional and non-depositional cases. This is related to the fact that in the case of higher flow rate more pressure drop is needed.

Figures $10 \mathrm{~A}$ and $10 \mathrm{~B}$ show the suspended asphaltene saturation at 5000 STBD near the wellbore region for depositional and non-depositional cases, respectively. As can be seen at a specific time, the trends of suspended asphaltene

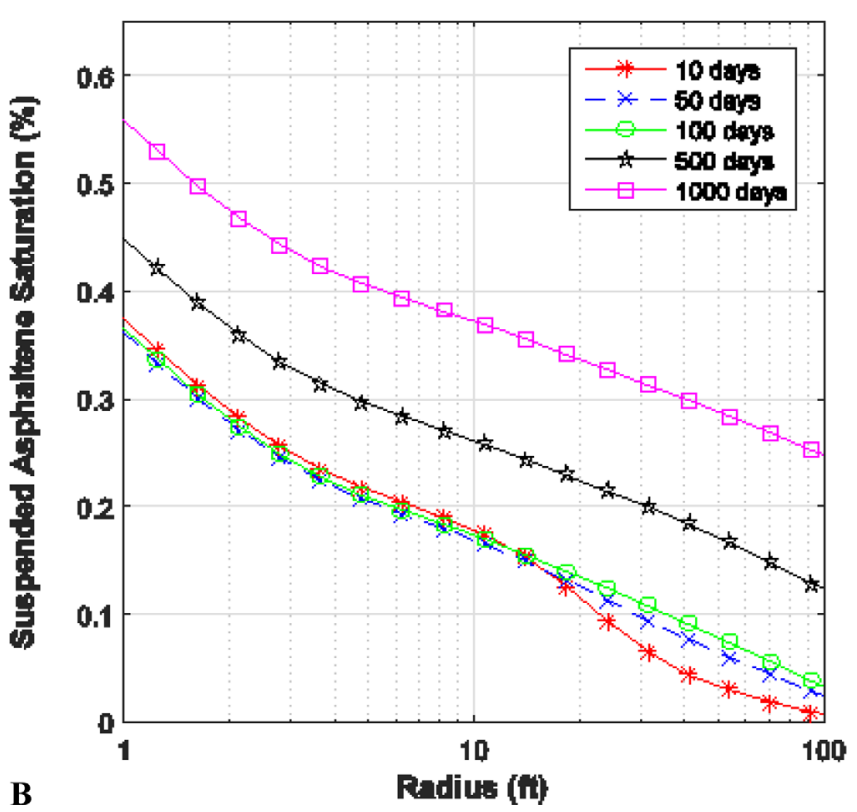

Fig. 9. Saturation of suspended asphaltene at 3000 STBD for (A) depositional case, (B) non-depositional case.

quantity with distance from the near wellbore region is reversed compared to its trend at farther radiuses. Near wellbore pressure is above the bubble point pressure up to 500 days, and asphaltene deposition mechanism is similar to the case of 3000 STBD. By passage of time, the pressure of the near wellbore region decreases and drops below the bubble point pressure that results in releasing gas. Thus, due to increase of asphaltene solubility in oil phase, the amount of precipitated asphaltene decreases. In general, an increase in oil flow rate causes more asphaltene deposition in the areas away from the near wellbore region. 

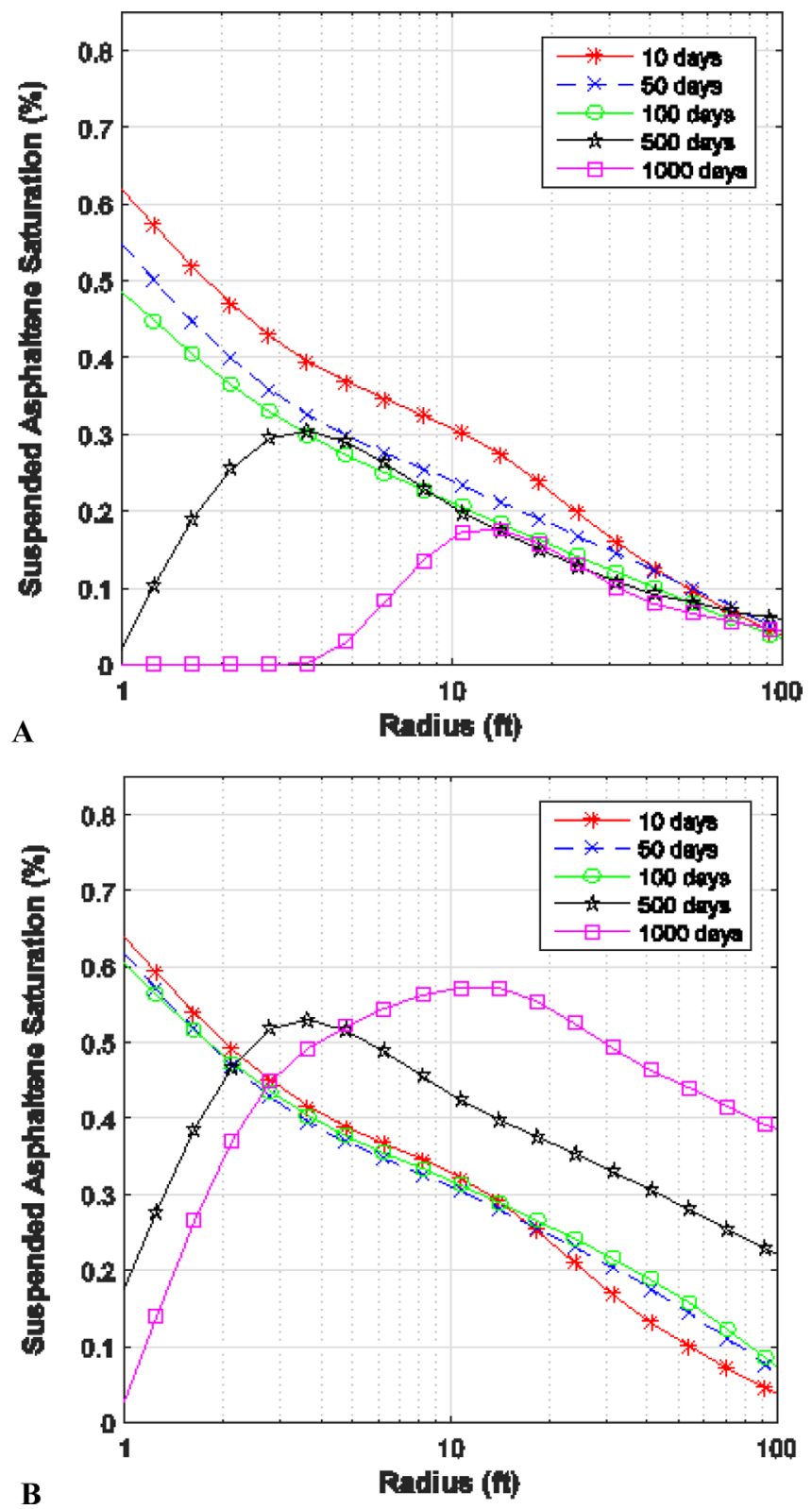

Fig. 10. Saturation of suspended asphaltene at 5000 STBD for (A) depositional case, (B) non-depositional case.

\subsection{Porosity and permeability reduction}

Figures $11 \mathrm{~A}-11 \mathrm{C}$ show the porosity reduction for oil flow rates of 1000,3000 and 5000 STBD, respectively. The amount of deposited asphaltene is increased over time. This leads to the reduction of pore volumes of the reservoir formation due to its occupation by deposited asphaltene. Until reservoir fluid pressure through formation is above bubble point pressure, severe pressure drop in the near wellbore area leads to increase in the deposited asphaltene value. This results in more porosity reduction compared to regions far away from the wellbores with lower pressure drop. Comparison of Figures $11 \mathrm{~A}$ and $11 \mathrm{~B}$ show since more pressure drop is necessary for increasing oil flow rates from
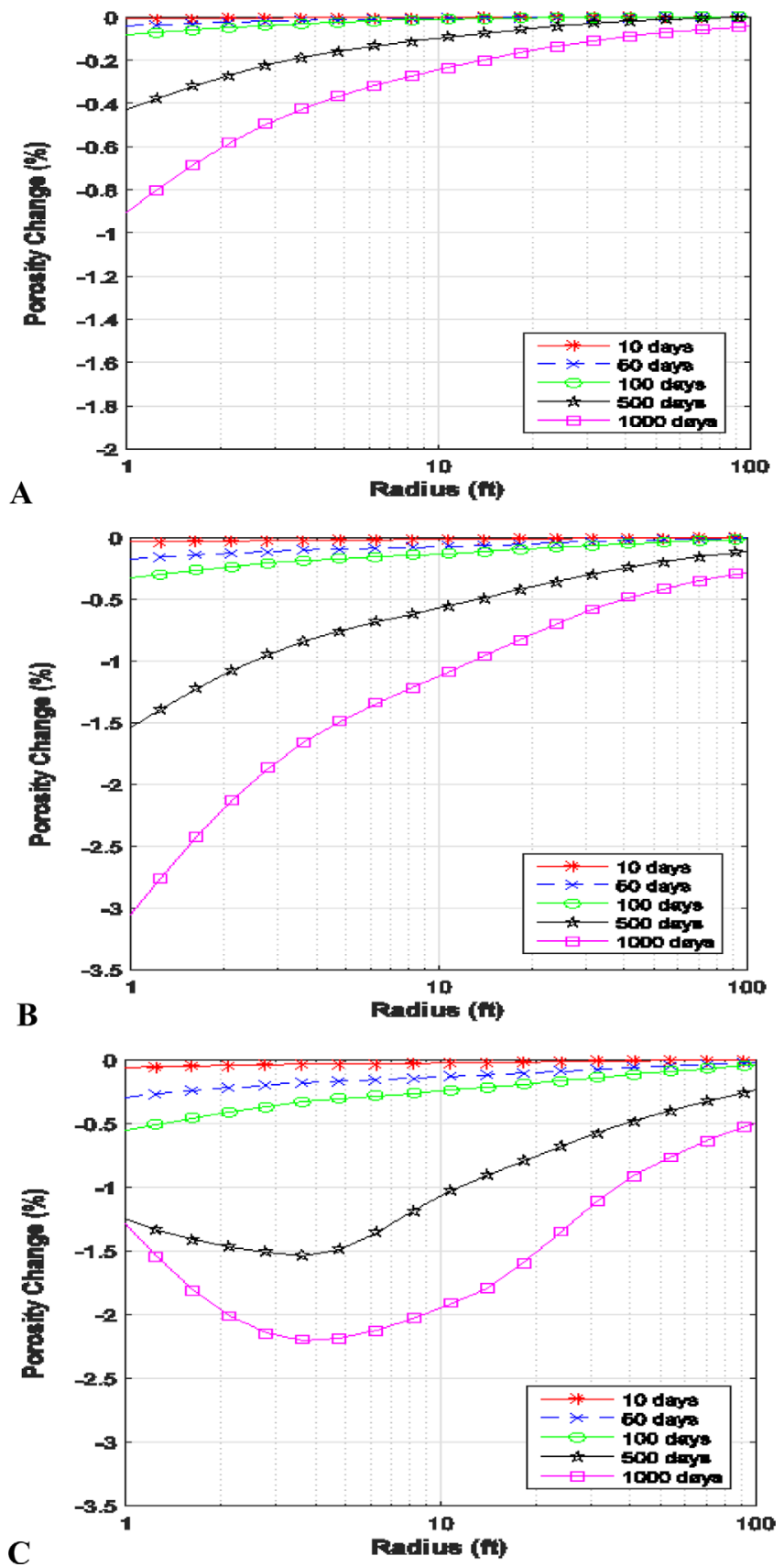

Fig. 11. Porosity reduction through formation for depositional case at (A) 1000 STBD, (B) 3000 STBD, (C) 5000 STBD.

1000 STBD to 3000 STBD, the higher asphaltene deposition hence more porosity reduction occurs.

An increase in oil flow rate up to 5000 STBD causes the near wellbore pressure falls below the bubble point pressure. The heavy fraction solubility in the oil phase is increased due to release light gas molecules from oil phase that are known as asphaltene precipitants. Although over time the deposited asphaltene will be increased at any radius, the deposition of asphaltene at the near wellbore regions is reduced compared to other areas far from the wellbore as a result of releasing gas. After releasing gas at higher flow 

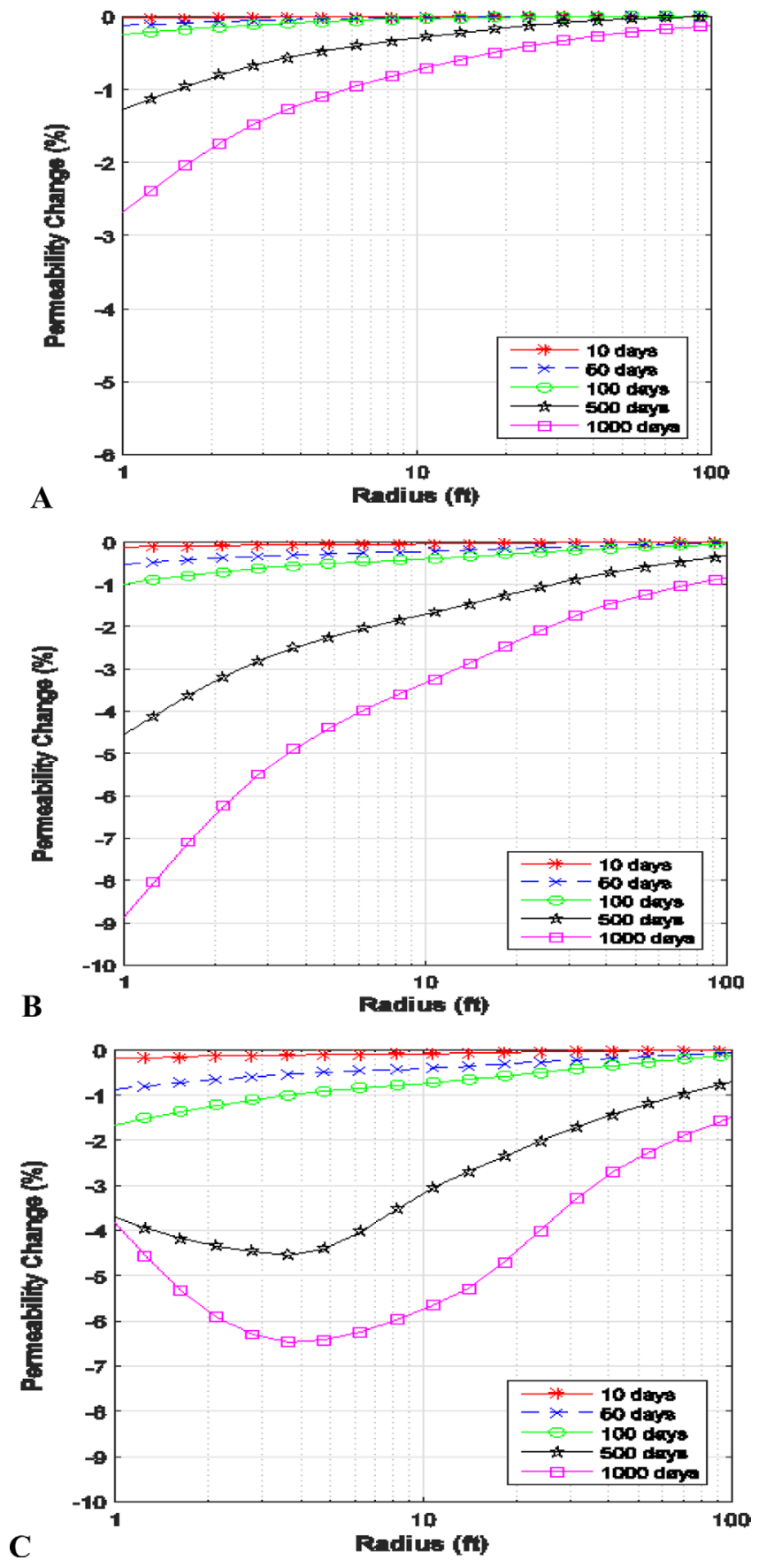

Fig. 12. Permeability reduction through formation for depositional case at (A)1000 STBD, (B)3000 STBD, (C) 5000 STBD.

rates, porosity reduction is lower at the near wellbore regions compared to farther regions, but this occurred porosity reduction will not return to its original value over time, and at the best state this reduction will be stopped. The amount of deposited asphaltene is increased by time, and pore volume of the reservoir rock is decreased which results in reduction of the porosity of the formation.

Figures $12 \mathrm{~A}$ and $12 \mathrm{~B}$ show the permeability reduction at near wellbore regions for the cases of 1000 and 3000 STBD,

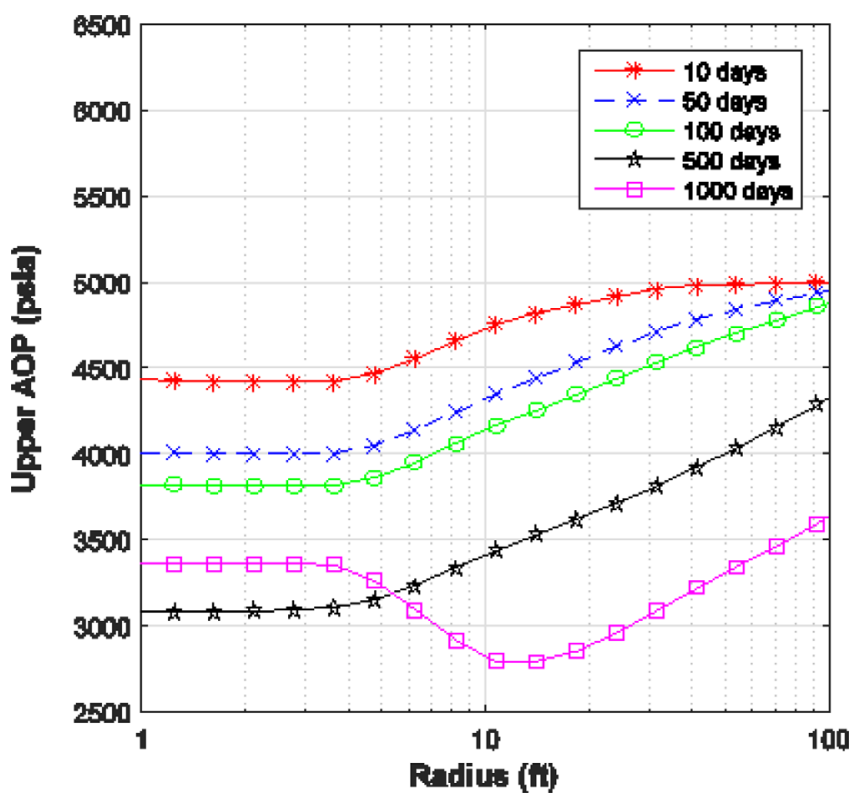

Fig. 13. Variation of UAOP through formation at different times for depositional case.

respectively. At near wellbore region, due to severe pressure drop, more asphaltene deposition occurs so permeability is decreased greatly compared to far radiuses. Comparison of these figures demonstrates that by increase in oil flow rate from $1000 \mathrm{STBD}$ to $3000 \mathrm{STBD}$, permeability is reduced much more due to higher pressure drop and higher asphaltene deposition.

Figure $12 \mathrm{C}$ shows the permeability changes at flow rate of 5000 STBD. Increase of oil flow rate up to 5000 STBD reduces the near wellbore pressure to fall below bubble point. This reduction of pressure results to more solubility of high molecular weight molecules in crude oil. Thus, the amount of deposited asphaltene in the near wellbore regions is decreased compared to far places from the wellbore area. Over time, at any wellbore radiuses, the amount of deposited asphaltene will be increased. Although at higher oil flow rates and at near wellbore areas the permeability reduction is lower compared to other areas far away from wellbore, this occurred permeability reduction will not return to its original permeability over time. As can be seen in Figure 12C permeability reduction can be stopped in the best state. At the radius of 1 foot, after approximately 400 days of production the permeability reduction is stopped.

\subsection{The effect of time on the pressure behavior}

Figure 13 shows the UAOP through formation at different times. After approximately 10 days of production with production flow rates of 5000 STBD, the near wellbore pressure is dropped under UAOP, and as a consequence, asphaltene starts to precipitate. At the same time at which the equilibrium of near wellbore crude oil is disturbed and asphaltene starts to deposition, at farther distances from the wellbore the lower change in the crude oil composition is occurred. 

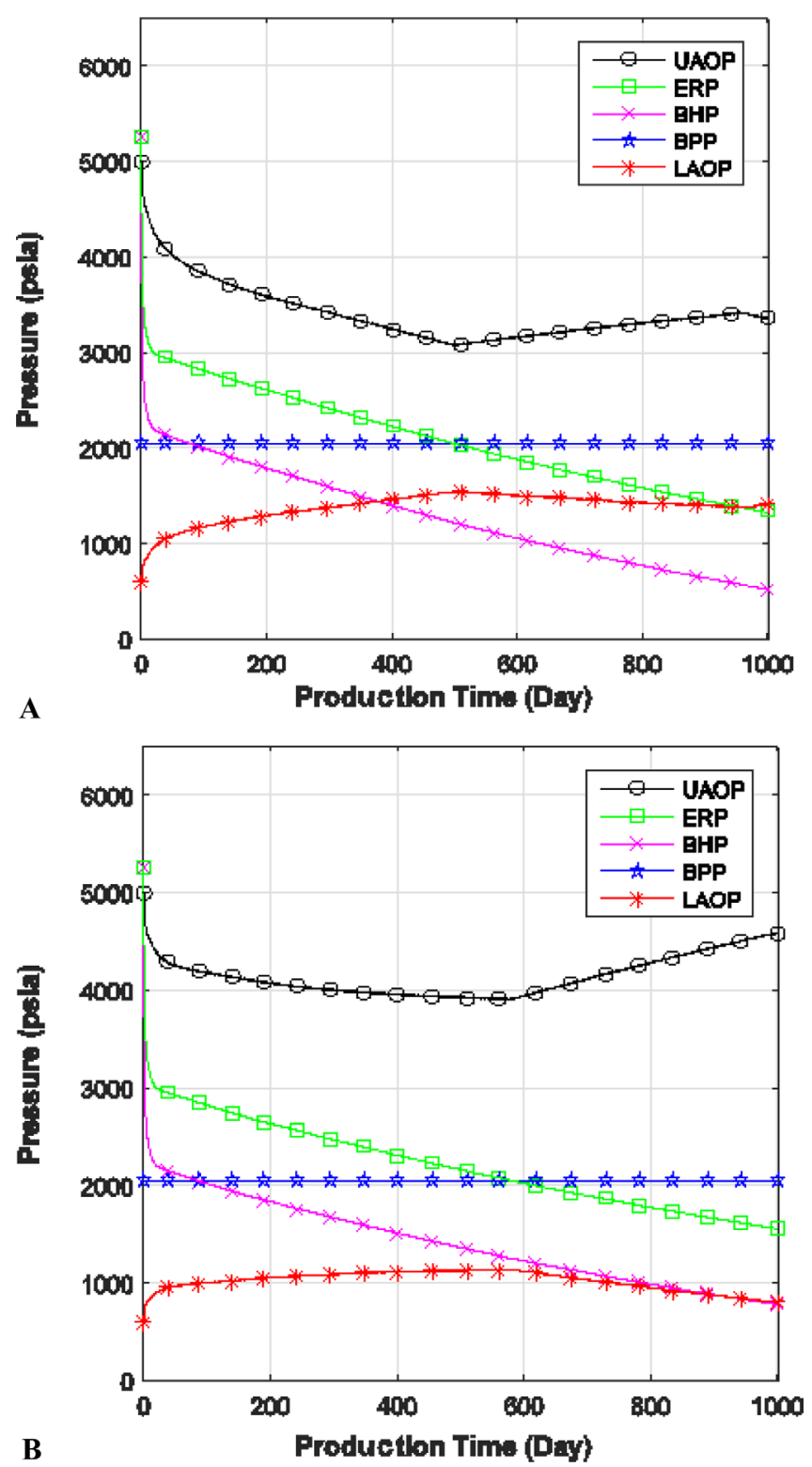

Fig. 14. Effect of production time on the pressure of equilibrium area at 5000 STBD for (A) depositional case, (B) nondepositional case.

Over time, the amount of deposited asphaltene is increased and the composition of the oil phase is changed more which results in change in the Pressure-VolumeTemperature (PVT) properties of the oil phase. UAOP is one of important PVT properties of crude oil which is known as a representation of threshold pressure at which asphaltene starts to precipitate. UAOP decreases as the amount of dissolved asphaltene in crude oil reduces. After a specific time, the near wellbore pressure completely drops below bubble point pressure. Thus, due to releasing the gas that causes change in the trend of asphaltene solubility in oil phase, the precipitated asphaltene starts to dissolve back into oil phase which means increase in the threshold pressure of asphaltene precipitation by time. However, this increment occurs only near wellbore region at which reservoir fluid pressure is lower than bubble point pressure and gas releases from oil phase (the times is over than 500 days).

Figures $14 \mathrm{~A}$ and $14 \mathrm{~B}$ show the different pressures behaviors of equilibrium area with passage of time at oil flow rate of 5000 STBD for both depositional and nondepositional cases, respectively. As can be seen, in the depositional case the fluid properties such as LAOP and UAOP have been more changed. After 100 days of production, the wellbore pressure drops under bubble point pressure but as can be seen UAOP reduces continuously therefore deposition of asphaltene around wellbore continued. After 500 days of production, the pressure of the equilibrium radius drops under bubble point pressure, at this state deposition of asphaltene is stopped and precipitated asphaltene starts to dissolve back into oil phase, therefore at this point the trend of LAOP and UAOP behavior is inversed. After around 950 days of production, the pressure of the equilibrium area drops under LAOP, and there is no suspended asphaltene at the equilibrium area. As a result, asphaltene dissolving back into oil phase is stopped which causes changes in the UAOP trend.

In the non-depositional case (Fig. 14B), the pressure of the equilibrium area drops under bubble point pressure at 600 days of production in which it is later compared to depositional case. Also, from comparison of depositional and non-depositional cases, it can be found that intensity of changes in fluid properties such as UAOP and LAOP is lower. The point that should be noted is that at the well radius in which the fluid pressure is lied on the LAOP at the 800 days of production, the amount of suspended asphaltene is exactly zero.

\section{Conclusion}

In this study, the effects of production rate, free gas and production time on the asphaltene precipitation and deposition, porosity and permeability reduction and reservoir fluid pressures behaviors were studied through the proposed model. This model was developed on two depositional and non-depositional cases. Based on this study, the following results can be drown:

- By increasing oil flow rates in under-saturated oil reservoirs, until reservoir fluid pressure through formation is above bubble point pressure, asphaltene precipitates and deposits in the reservoir. However, after falling reservoir fluid pressure bellow bubble point pressure, the suspended precipitated asphaltene starts to dissolving back into the oil phase.

- As oil flow rate was increased from 1000 to 3000 STBD, suspended asphaltene near wellbore areas is increased. However, an increase in oil flow rate from 3000 to 5000 STBD causes reservoir pressure to fall below bubble point. This phenomenon leads to reduction of the suspended asphaltene value. This is due to the fact that precipitated asphaltene was forced to dissolve again into the oil phase. 
- By releasing gas from the oil phase and dissolving back of precipitated asphaltene into the oil phase which occurs at high flow rates, suspended asphaltene vanishes completely. Also, porosity and permeability are improved, but due to deposition of asphaltene they do not return to their original values.

- There is an area near wellbore region known as equilibrium region that high fluid velocity in this area causes the fluid properties such as UAOP and LAOP be constant.

- In equilibrium region, UAOP decreases over time due to deposition of asphaltene. Furthermore, UAOP increases as the equilibrium region pressure drops under bubble point pressure due to dissolving back of suspended asphaltene into the oil phase.

\section{References}

1 Wang S., Civan F. (2001) Productivity decline of vertical and horizontal wells by asphaltene deposition in petroleum reservoirs, SPE International Symposium on Oilfield Chemistry, Society of Petroleum Engineers.

2 Hirschberg A., DeJong L.N.J., Schipper B.A., Meijer J.G. (1984) Influence of temperature and pressure on asphaltene flocculation, Soc. Petrol. Eng. J. 24, 03, 283-293.

3 Burke N.E., Hobbs R.E., Kashou S.F. (1990) Measurement and Modeling of Asphaltene Precipitation (includes associated paper 23831), J. Petrol. Technol. 42, 11, 1440-1446.

4 De Boer R.B., Leerlooyer K., Eigner M.R.P., Van Bergen A.R.D (1995) Screening of crude oils for asphalt precipitation: theory, practice, and the selection of inhibitors, SPE Prod. Facil. 10, 01, 55-61.

5 Andersen S.I., Speight J.G. (1999) Thermodynamic models for asphaltene solubility and precipitation, J. Petrol. Sci. Eng. 22, 1, 53-66.

6 Thomas F., Bennion D.B., Bennion D.W., Hunter B.E. (1992) Experimental and theoretical studies of solids precipitation from reservoir fluid, J. Can. Petrol. Technol. 31, 01, 35-45.

7 Leontaritis K.J. (2005) Asphaltene near-well-bore formation damage modeling, J. Energy Resour. Technol. 127, 3, 191200.

8 Peramanu S., Clarke P.F., Pruden B.B. (1999) Flow loop apparatus to study the effect of solvent, temperature and additives on asphaltene precipitation, J. Petrol. Sci. Eng. 23, 2, 133-143.

9 Zheng C., Zhu M., Zhou W., Zhang D. (2017) A Preliminary Investigation Into the Characterization of Asphaltenes Extracted From an Oil Sand and Two Vacuum Residues From Petroleum Refining Using Nuclear Magnetic Resonance, DEPT, and MALDI-TOF, J. Energy Resour. Technol. 139, 3, 032905 .

10 Davarpanah L., Vahabzadeh F., Dermanaki A. (2015) Structural study of asphaltenes from Iranian heavy crude oil, Oil Gas Sci. Technol. - Rev. IFP Energies nouvelles 70, 6, 1035-1049.

11 Kohse B.F., Kohse B.F., Nghiem L.X. (2004) Modelling asphaltene precipitation and deposition in a compositional reservoir simulator, SPE/DOE Symposium on Improved Oil Recovery, Society of Petroleum Engineers.
12 Fukumoto A., Dalmazzone C., Frot D., Barré L., Noïk C. (2018) Characterization of Complex Crude Oil Microemulsions-DSC Contribution, Oil Gas Sci. Technol. - Rev. IFP Energies nouvelles $\mathbf{7 3}, 3$.

13 Mitchell D.L., Speight J.G. (1973) The solubility of asphaltenes in hydrocarbon solvents, Fuel 52, 2, 149-152.

14 Mohammed S.A.A., Arisaka K., Kumazaki Y. (1998) Integrated analysis of asphaltene deposition from field production data and laboratory experiments, Abu Dhabi International Petroleum Exhibition and Conference, Society of Petroleum Engineers.

15 Almehaideb R.A. (2004) Asphaltene precipitation and deposition in the near wellbore region: a modeling approach, $J$. Petrol. Sci. Eng. 42, 2, 157-170.

16 Pedersen K.S., Christensen P.L., Shaikh J.A. (2014) Phase behavior of petroleum reservoir fluids, CRC Press: USA.

17 Pan H., Firoozabadi A. (1997) Thermodynamic micellization model for asphaltene precipitation from reservoir crudes at high pressures and temperatures, SPE Annual Technical Conference and Exhibition, Society of Petroleum Engineers.

18 Pan H., Firoozabadi A. (1998) A thermodynamic micellization model for asphaltene precipitation: Part I: Micellar size and growth, SPE Prod. Facil. 13, 02, 118-127.

19 Nghiem L.X., Coombe D.A. (1997) Modelling asphaltene precipitation during primary depletion, SPE J. 2, 02, 170176.

20 Nghiem L.X., Coombe D.A., Ali S. (1998) Compositional simulation of asphaltene deposition and plugging, SPE Annual Technical Conference and Exhibition, Society of Petroleum Engineers.

21 Kohse B.F., Nghiem L.X., Maeda H., Ohno K. (2000) Modelling phase behaviour including the effect of pressure and temperature on asphaltene precipitation, SPE Asia Pacific Oil and Gas Conference and Exhibition, Society of Petroleum Engineers.

22 Wang S., Civan F. (2005) Modeling formation damage by asphaltene deposition during primary oil recovery, J. Energy Resour. Technol. 127, 4, 310-317.

23 Civan F. (1995) Modeling and simulation of formation damage by organic deposition, Proceedings of the First International Symposium on Colloid Chemistry in Oil Production: Asphaltenes and Wax Deposition, ISCOP'95, Rio de Janeiro, Brazil, November 26-29, pp. 102-107.

24 Mansoori G.A. (1997) Modeling of asphaltene and other heavy organic depositions, J. Petrol. Sci. Eng. 17, 1, 101-111.

25 Hutin A., Argillier J.F., Langevin D. (2016) Influence of pH on oil-water interfacial tension and mass transfer for asphaltenes model oils. Comparison with crude oil behavior, Oil Gas Sci. Technol. - Rev. IFP Energies nouvelles 71, 4, 58.

26 Manshad A.K., Rostami H., Rezaei H., Hosseini S.M. (2015) Application of artificial neural network-particle swarm optimization algorithm for prediction of asphaltene precipitation during gas injection process and comparison with Gaussian process algorithm, J. Energy Resour. Technol. 137, 6, 062904.

27 Bahrami P., Kharrat R., Mahdavi S., Firoozinia H. (2015) Prediction of the gas injection effect on the asphaltene phase envelope, Oil Gas Sci. Technol. - Rev. IFP Energies nouvelles 70, 6, 1075-1086.

28 Srivastava R.K., Huang S.S. (1997) Asphaltene deposition during $\mathrm{CO}_{2}$ flooding: a laboratory assessment, SPE Production Operations Symposium, Society of Petroleum Engineers. 
29 Wang S., Civan F. (2005) Model-assisted analysis of simultaneous paraffin and asphaltene deposition in laboratory core tests, J. Energy Resour. Technol. 127, 4, 318-322.

30 Papadimitriou N., Romanos G.E., Charalambopoulou G.C., Kainourgiakis M.E., Katsaros F.K., Stubos A.K. (2007) Experimental investigation of asphaltene deposition mechanism during oil flow in core samples, J. Petrol. Sci. Eng. 57, 3, 281-293.

31 Mousavi S., et al. (2012) Comparison of ultrasonic wave radiation effects on asphaltene aggregation in toluene-pentane mixture between heavy and extra heavy crude oils, $J$. Energy Resour. Technol. 134, 2, 022001.

32 Solaimany-Nazar A.R., Zonnouri A. (2011) Modeling of asphaltene deposition in oil reservoirs during primary oil recovery, J. Petrol. Sci. Eng. 75, 3, 251-259.

33 Kazemzadeh Y., Malayeri M.R., Riazi M., Parsaei R. (2015) Impact of $\mathrm{Fe}_{3} \mathrm{O}_{4}$ nanoparticles on asphaltene precipitation during $\mathrm{CO}_{2}$ injection, J. Nat. Gas Sci. Eng. 22, 227-234.

34 Kashefi S., Lotfollahi M.N., Shahrabadi A. (2018) Investigation of asphaltene adsorption onto zeolite beta nanoparticles to reduce asphaltene deposition in a silica sand pack, Oil Gas Sci. Technol. - Rev. IFP Energies nouvelles 73, 2.

35 Rezakazemi M., Mirzaei S., Asghari M., Ivakpour J. (2017) Aluminum oxide nanoparticles for highly efficient asphaltene separation from crude oil using ceramic membrane technology, Oil Gas Sci. Technol. - Rev. IFP Energies nouvelles 72, 6, 34.

36 Nghiem L., Hassam M.S., Nutakki R., George A.E.D. (1993) Efficient modelling of asphaltene precipitation, SPE Annual
Technical Conference and Exhibition, Society of Petroleum Engineers.

37 Peng D.-Y., Robinson D.B. (1976) A new two-constant equation of state, Ind. Eng. Chem. Fundam. 15, 1, 59-64.

38 Whitson C.H. (1983) Characterizing hydrocarbon plus fractions, Soc. Petrol. Eng. J. 23, 04, 683-694.

39 Lee B., Kesler M. (1980) Improve vapor-pressures prediction, Hydrocarbon Processing 60, 7, 163-167.

40 Twu C.H. (1984) An internally consistent correlation for predicting the critical properties and molecular weights of petroleum and coal-tar liquids, Fluid Phase Equilib. 16, 2, $137-150$.

41 Danesh A. (1998) PVT and phase behaviour of petroleum reservoir fluids, Vol. 47, Elsevier: USA.

42 Chueh P.L., Prausnitz J. (1967) Vapor-liquid equilibria at high pressures: Calculation of partial molar volumes in nonpolar liquid mixtures, AIChE J. 13, 6, 1099-1107.

43 Ali M., Islam M. (1998) The effect of asphaltene precipitation on carbonate-rock permeability: an experimental and numerical approach, SPE Prod. Facil. 13, 03, 178-183.

44 Minssieux L., Nabzar L., Chauveteau G., Longeron D., Bensalem R. (1998) Permeability damage due to asphaltene deposition: Experimental and modeling aspects, Revue de l'Institut Français du Pétrole 53, 3, 313-327.

45 Civan F., Knapp R.M., Ohen H.A. (1989) Alteration of permeability by fine particle processes, J. Petrol. Sci. Eng. 3, $1-2,65-79$. 